\title{
Wikis como herramientas de trabajo colaborativo complementario y desarrollo de recursos para la formación en traducción a nivel universitario: análisis retrospectivo
}

\section{Wikis as complementary collaborative work tools and development of training resources in translation at university level: retrospective analysis}

\author{
Bianca Vitalaru \\ Universidad de Alcalá, Alcalá de Henares, España \\ bianca.vitalaru@gmail.com
}

\begin{abstract}
Resumen
Este artículo tiene dos objetivos. En primer lugar, nos hemos propuesto hacer un análisis retrospectivo de los diferentes tipos de actividades realizadas con alumnos de un Máster de Traducción e Interpretación para desarrollar la habilidad de trabajo en grupo utilizando nuevas tecnologías. Esta habilidad forma parte de la competencia interpersonal, fundamental para los traductores según la Red EMT de la Comisión Europea y en el contexto del Espacio Europeo de Educación Superior. En segundo lugar, nos interesa evaluar la utilidad de las herramientas wiki para facilitar el trabajo colaborativo en la creación/producción de recursos propios y de materiales bilingües/multilingües para personas en formación del campo de la TI en los servicios públicos (TISP). En este sentido, tendremos en cuenta el tipo de tarea, las adaptaciones y cambios de los diferentes cursos académicos en los que se ha implementado desde 2007 hasta 2011 y las habilidades desarrolladas por los alumnos. Finalmente, propondremos unas reflexiones y recomendaciones generales.

Palabras clave: herramientas wiki, trabajo colaborativo, traductores e intérpretes, redacción de contenido, glosarios.
\end{abstract}

\begin{abstract}
This article has two objectives. First, to make a retrospective analysis of the different types of activities carried out with students of a Translation and Interpreting Master in order to develop the ability to work in groups using new technologies. This skill is part of the interpersonal competence, which is fundamental for translators according to the EMT Network of the European Commission and in the context of the European Higher Education Area. Second, we are interested in evaluating the usefulness of the wiki tools to facilitate collaborative work in the creation/production of the students' own resources and bilingual/multilingual materials for students in the field of community interpreting (PSIT). In this sense, we will take into account the type of task, the adaptations and changes made in the different academic years in which it has been implemented from 2007 to 2011 and the skills developed by the students. Finally, we will include some reflections and general recommendations.
\end{abstract}

Keywords: wiki tools, collaborative work, translators and interpreters, collaborative writing, glossaries.

\section{Introducción}

La capacidad de trabajo en grupo es una de las competencias fundamentales en el contexto del Espacio Europeo de Educación Superior, enfocado en cambios metodológicos en la docencia de modo que el alumno sea protagonista de su propio proceso de aprendizaje, y una de las competencias básicas de los estudios universitarios oficiales de postgrado según el Real Decreto 1027/2011, de 15 de julio, por el que se establece el Marco Español de Cualificaciones para la Educación Superior: 
f) haber desarrollado la autonomía suficiente para participar en proyectos de investigación y colaboraciones científicas o tecnológicas dentro su ámbito temático, en contextos interdisciplinares $\mathrm{y}$, en su caso, con una alta componente de transferencia del conocimiento (MECES, 2011: nivel 3).

Montenegro y Pujol (2010: 2) señalan diferentes documentos en los que ya se recogía el trabajo colaborativo como competencia básica en el aprendizaje: Marco de convergencia europeo de ANECA (2003) ${ }^{1}$ y como competencia interpersonal en el proyecto Tuning Educational Structures in Europe (González y Wagenaar, 2003: 81$84)$.

Además, en el área de traducción, el trabajo en grupo es una de las habilidades fundamentales de la competencia personal e interpersonal del marco de competencias de la Red de Másteres Europeos de Traducción (EMT) actualizado en 2017, entre las siguientes habilidades que pueden considerarse como estrechamente relacionadas con esta capacidad principal [negrita del autor]:

\section{STUDENTS KNOW HOW TO...}

21 Plan and manage time, stress and workload

22 Comply with deadlines, instructions and specifications

23 Work in a team, including, where appropriate, in virtual, multicultural and multilingual environments, using current communication technologies

24 Use social media responsibly for professional purposes

26 Continuously self-evaluate, update and develop competences and skills through personal strategies and collaborative learning

(EMT Competence Framework, 2017: 10)

Finalmente, una de las estrategias de re-conceptualización de la enseñanza universitaria, es, según la Asociación de Universidades Europeas (2016, citada por Ferreira-Lopes, Bezanilla, y Elexpuru, 2018: 2), la internacionalización y preparación de los alumnos para trabajar en un mundo globalizado. La movilidad virtual es una de las consecuencias de esta estrategia adoptada especialmente para desarrollar competencias del siglo XXI como la colaboración, la alfabetización digital y la competencia intercultural. Eso significa que conectarse a espacios virtuales de aprendizaje implica, entre otros aspectos, la oportunidad de aprender de entornos culturales y promover cambios culturales (Ferreira-Lopes, Bezanilla, y Elexpuru, 2018: 2). Este contexto es particularmente relevante si los participantes provienen de diferentes culturas y el aprendizaje requiere la comunicación de los alumnos por grupos de trabajo para construir conocimiento. Se podría incluso afirmar que el trabajo en grupo en ese tipo de entorno virtual contribuye al desarrollo de parte de la competencia intercultural.

En este contexto cabe señalar que, en las últimas décadas, con la llegada a España de personas de diferentes orígenes, especialmente del centro y este de Europa y África, el tema de las dificultades de tipo lingüístico y cultural ha afectado especialmente la comunicación con proveedores de servicios públicos en ámbitos como el educativo, el administrativo, el sanitario o el jurídico, en la realización de trámites

\footnotetext{
${ }^{1}$ Programa de Convergencia Europea. El crédito europeo. Madrid: Agencia Nacional de Evaluación de la Calidad y Acreditación. 2003.
}

Wikis como herramientas de trabajo colaborativo complementario y desarrollo de recursos para la formación en traducción a nivel universitario: análisis retrospectivo Bianca Vitalaru. Página 2 de 47 
imprescindibles para una buena convivencia social. Desde este punto de vista, el Grupo FITISPos-UAH ${ }^{2}$ ha analizado, entre otros aspectos y desde diferentes perspectivas, la calidad de la comunicación en los servicios públicos en contextos multiculturales en los que interviene población de origen extranjero. Algunos de sus estudios subrayan la gran demanda de medios de intermediación entre los proveedores de servicios públicos y los usuarios de diferentes culturas y, por otro lado, su propio interés para encontrar medidas adecuadas para evitar este tipo de problemas que pueden tener consecuencias graves a nivel administrativo, sanitario o jurídico, ha ido creciendo (estudios de Valero-Garcés et al, 2011; 2014; 2017).

Entre las medidas adoptadas en este sentido destacan tres líneas fundamentales de trabajo: a) la formación a nivel de postgrado de especialistas/profesionales en traducción o interpretación en los servicios públicos que actúen de enlace ${ }^{3}$; b) la facilitación del diálogo entre investigadores, profesores y especialistas en diferentes materias mediante un congreso internacional sobre TISP que se celebra cada tres años; y c) la elaboración de materiales específicos para la formación de esos profesionales, que son muy escasos en algunas combinaciones de lenguas, como, por ejemplo, en español-rumano/polaco/árabe/chino/ruso y bastante productivos en otras como en español-inglés/francés, tal y como se puede observar en las investigaciones del grupo ${ }^{4}$. La autora de este artículo es miembro del mismo grupo de investigación, así como de los grupos de innovación docente FILWIT $^{5}$, que investiga con respecto a la utilidad de las herramientas wikis en la enseñanza universitaria, y FITISPos-E-Learning ${ }^{6}$, que investiga sobre la aplicabilidad de diferentes tipos de nuevas tecnologías en la formación de traductores e intérpretes en los servicios públicos y trabaja en la actualización constante de un repositorio de actividades para el autoaprendizaje y para la formación continua.

Este artículo tiene dos objetivos. En primer lugar, nos hemos propuesto hacer un análisis retrospectivo de los diferentes tipos de actividades realizadas para desarrollar la capacidad de trabajo en grupo utilizando nuevas tecnologías en los alumnos del Máster Universitario en Comunicación Intercultural, Interpretación y Traducción en los Servicios Públicos (Máster TISP) como parte de la competencia interpersonal, fundamental para los traductores según la Red EMT. En segundo lugar, nos interesa evaluar la utilidad de las herramientas wiki para facilitar el trabajo colaborativo en la creación/producción de recursos propios y materiales bilingües/multilinguies para personas en formación en el campo de la TISP. En este sentido, tendremos en cuenta el tipo de tarea, las adaptaciones y cambios de los diferentes cursos académicos en los que se ha implementado desde 2007 hasta 2011 y las habilidades desarrolladas por los alumnos. Finalmente, propondremos unas reflexiones y recomendaciones generales. En el contexto laboral actual de los traductores parece innecesario subrayar que las habilidades implicadas - de trabajo en grupo y desarrollo de recursos propios- utilizando

\footnotetext{
${ }^{2}$ Formación e Investigación en Traducción e Interpretación en los Servicios Públicos, Ref. CCHH2006/R04). http://www3.uah.es/traduccion

${ }^{3}$ Máster Universitario en Comunicación Intercultural, Interpretación y Traducción en los Servicios Públicos (Máster TISP) en diferentes pares de lenguas en la Universidad de Alcalá desde el año 2006 como oficial/universitario

${ }^{4}$ https://www.uah.es/es/investigacion/unidades-de-investigacion/grupos-de-investigacion/Formacion-einvestigacion-en-traduccion-e-interpretacion-en-los-servicios-publicos/\#Articulos

${ }^{5} \mathrm{https}$ ///www3.uah.es/ice/ID/documentos/GGI_plantilla.pdf

${ }^{6}$ https://www3.uah.es/ice/ID/documentos/GGI_plantilla.pdf
}

Wikis como herramientas de trabajo colaborativo complementario y desarrollo de recursos para la formación en traducción a nivel universitario: análisis retrospectivo Bianca Vitalaru. Página 3 de 47 
las nuevas tecnologías son fundamentales en la vida profesional del traductor especializado, por lo que es esencial que los estudiantes las adquieran y entiendan sus implicaciones para poder desenvolverse con soltura en el ámbito laboral.

\title{
2. Potencial como herramientas de trabajo colaborativo: estudios representativos
}

Las herramientas que son objeto de estudio en este artículo se definen como instrumentos de la Web 2.0 (Anderson, 2007: 1), la Web creada por y para los usuarios, de edición fácil, abierta y rápida, que se utilizan para la creación de diferentes tipos de contenido en Internet, normalmente como resultado de la colaboración y comunicación de los individuos. Se podría afirmar que los dos conceptos del contexto que ha impulsado su creación también pueden considerarse como características definitorias: "solución" a "la necesidad de compartir online un documento abierto a las modificaciones y sugerencias de un grupo de colaboradores" y "principio de diseño [...] KISSSS: Keep it Short, Simple, Small and Self-contained/Mantenlo corto, simple, pequeño y auto contenido" (Ludo, 2007: 1, 2 citado por Vitalaru, 2009). Prácticamente, como indican Montenegro y Pujol (2010: 1) se trata de una herramienta que facilita "la escritura colaborativa" y que permite monitorizar el trabajo de los participantes:

\begin{abstract}
La herramienta wiki consiste en una página virtual para la escritura colaborativa, en la cual cada una de las personas que participa puede ir añadiendo y cambiando los contenidos de la página. Esta herramienta permite recoger el proceso de construcción del texto, visualizando las formas de trabajo de los estudiantes, guardando un historial de las diferentes versiones y las aportaciones realizadas por cada participante.
\end{abstract}

El potencial de las wikis como herramientas de trabajo colaborativo a nivel universitario es un tema tratado en muchos estudios que explican su aplicación, sus ventajas y utilidad docente en asignaturas de diferentes áreas principalmente en el contexto de los cambios metodológicos educativos y de la utilidad de la Web 2.0. Considerando los objetivos de este trabajo, mencionaremos algunos de los estudios disponibles en línea más representativos, desde los más generales, que subrayan su aplicabilidad para el trabajo colaborativo, hasta los más específicos para nuestro tema, es decir, relacionados con su utilidad en la enseñanza de lenguas extranjeras o de la traducción. Estas últimas dos áreas nos interesan por tratarse de dos áreas de la lingüística aplicada bastante relacionadas, de la cual la traducción es, en este caso, la más específica.

\subsection{Estudios sobre implementación de wikis en diferentes áreas}

De los estudios que se centran específicamente en el trabajo colaborativo como característica fundamental y la analizan en diferentes tipos de asignaturas, hemos seleccionado a aquellos que destacan diferentes enfoques o elementos relacionados con el tema. Por lo tanto, los aspectos destacados son los efectos sobre el proceso de enseñanza, el desarrollo de diferentes matices que caracterizan la competencia en sí y la descripción de estrategias para fomentarlo.

Con respecto al primer aspecto, Montenegro y Pujol (2010: 1-15) describen el proceso seguido en la implementación de la herramienta wiki mediante la plataforma

Wikis como herramientas de trabajo colaborativo complementario y desarrollo de recursos para la formación en traducción a nivel universitario: análisis retrospectivo Bianca Vitalaru. Página 4 de 47 
Moodle en diferentes asignaturas de la Licenciatura de Psicología de la Universidad Autónoma de Barcelona. Se destaca la utilidad para desarrollar habilidades específicas de trabajo en equipo, análisis, síntesis y expresión escrita y de "competencias encaminadas al desarrollo de procesos colectivos", pero también la necesidad de combinar su uso con otros métodos docentes presenciales (2010: 9).

En cuanto a los dos siguientes aspectos, el uso de la herramienta para el desarrollo de la competencia y sus matices, Perea González, Estrada Esquivel y Campos Méndez (2013: 98-109) se centran en el desarrollo del aprendizaje activo y significativo de alumno mientras que Meléndez (2015: 1-19) y Anguita Martínez et al. (2010: 2-19) en estrategias para propiciar el aprendizaje/trabajo colaborativo. A continuación, explicaremos algunos detalles más significativos.

Perea González, Estrada Esquivel y Campos Méndez (2013: 98-109) destacan la importancia del uso de las TIC en general y de los blogs y wikis en particular en la clase con alumnos de tercer cuatrimestre de la licenciatura en Estomatología de la Benemérita Universidad Autónoma de Puebla. Se recoge la percepción del alumnado, que valora los beneficios del uso de ambas herramientas y su aplicabilidad a la mejor organización de su propio trabajo. Los autores reflexionan sobre el trabajo colaborativo y el uso de las tecnologías en la educación con el fin de desarrollar el aprendizaje significativo basado en una serie de competencias y en el trabajo autónomo, reflexivo y activo.

Finalmente, Anguita Martínez et al. (2010: 2) reflexionan sobre la posibilidad de desarrollar el pensamiento crítico y fomentar el trabajo colaborativo del alumnado a través de un "proceso educativo basado en la colaboración mediada por tecnología" (8), principalmente la que caracteriza el entorno de las herramientas wiki. Finalmente, incluyen como "lecciones aprendidas" una serie de observaciones y recomendaciones prácticas para tener en cuenta de cara a la mejora posterior.

En cambio, los aspectos a los que el profesor debe prestar mucha atención ya que pueden ser problemáticos son los relacionados con el manejo eficaz de la herramienta y la evaluación correcta y adecuada del alumnado. Algunos de los elementos mencionados por Montenegro y Pujol (2010: 7-8) son [en cursiva en el documento original]:

- Expectativa de corrección de modo que su falta en ocasiones no influya en la desmotivación del alumno ni que implique una carga excesiva para el profesor.

- Volumen de información proporcionada.

- Dificultad en la evaluación del esfuerzo ya que es bastante laborioso el seguimiento individual y no necesariamente se refleja la dedicación de cada alumno ni la dinámica del trabajo seguida fuera del espacio virtual.

- Necesidad de que el trabajo no virtual también sea tenido en cuenta, es decir otros aspectos como "el reparto de tareas, el liderazgo, las discusiones presenciales o la competitividad grupal"

\subsection{Estudios sobre wikis en la enseñanza de lenguas extranjeras y traducción}

De los numerosos trabajos relacionados con el uso de las herramientas wiki para el aprendizaje de lenguas extranjeras el de Araujo Portugal (2014: 1-27) nos parece fundamental ya que realiza un repaso de una serie de estudios basados en el uso de las wikis (8-13), además de los blogs y las redes sociales, como herramientas

Wikis como herramientas de trabajo colaborativo complementario y desarrollo de recursos para la formación en traducción a nivel universitario: análisis retrospectivo Bianca Vitalaru. Página 5 de 47 
representativas de la Web 2.0, y elabora una tabla de usos, así como de ventajas e inconvenientes para cada una. Destaca la eficacia de las wikis para la autoría colectiva $\mathrm{y}$, basándose en los estudios de diferentes autores, subraya la variedad de las funciones que pueden tener en la enseñanza (9):

- Compartir materiales entre profesionales con los mismos intereses, dándolos, además, a conocer.

- Desarrollar la habilidad de trabajar de manera autónoma prestando atención al proceso de trabajo.

- Permitir la interacción asíncrona entre participantes en el proceso y que se beneficien de los resultados.

- Permitir la comunicación, colaboración y el debate.

Por otro lado, su utilización en actividades docentes de traducción y, en especial, de traducción especializada para potenciar el trabajo colaborativo, es menos frecuente. A continuación, mencionaremos algunos de los estudios más relevantes encontrados.

García Santiago (2016: 147-148) utiliza una wiki con alumnos de una asignatura dentro de los estudios de Traducción e Interpretación de la Universidad de Granada -el proyecto TradWiki- para el desarrollo de competencias enmarcado en la "formación y actualización del traductor" y como proyecto de innovación docente. Se utiliza una plataforma en línea que incorpora diferentes tipos de recursos de la Web 2.0 para optimizar el trabajo de los alumnos-traductores en equipo y se analizan tanto los hábitos de uso del alumnado como el aprendizaje adquirido como aspectos fundamentales del estudio. Podríamos resumir los objetivos en dos categorías: por un lado, conocer el funcionamiento de la herramienta y saber utilizar elementos de la Web $2.0 \mathrm{y}$, por otro, realizar tareas propias del proceso de traducción y del trabajo en grupo.

Otros trabajos relevantes son los de diferentes miembros del grupo de innovación docente FILWIT y FITISPos-UAH, que se centran en diferentes aspectos del trabajo con wikis en asignaturas de traducción a nivel universitario (grado y postgrado) o en la elaboración de diferentes tipos de wikis en diferentes cursos académicos. Encontramos desde temas más generales como la descripción general de un wiki piloto en un programa de postgrado y reflexiones iniciales sobre el potencial de la herramienta (Valero Garcés y Vitalaru, 2007) hasta más específicas como la aplicabilidad para la creación de materiales bilingües / multilingües para traductores de los servicios públicos (Vitalaru, 2009), para la elaboración de glosarios multilingües de utilidad en TISP (Vitalaru, Valero Garcés y Lázaro Gutiérrez, 2008) y para la elaboración de glosarios especializados individuales y colaborativos en asignaturas de traducción del mismo programa en diferentes cursos académicos (Vitalaru y Bodzer, 2012).

Por otro lado, se analizan las funciones pedagógicas de las herramientas en asignaturas de traducción de la Universidad de Alcalá (Mancho Barés, Vitalaru y Valero Garcés, 2008) y su utilidad para la escritura colaborativa en actividades de traducción de la asignatura de grado "Inglés para fines específicos" y de la asignatura "Comunicación

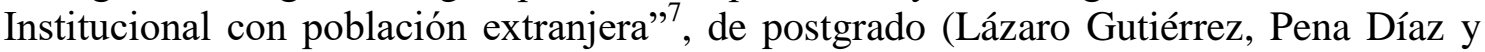
Vitalaru, 2009). En este mismo artículo también se analiza la utilidad de la tecnología wiki para funciones concretas como la elaboración de glosarios, la escritura

\footnotetext{
${ }^{7}$ Máster Universitario en Comunicación Intercultural, Interpretación y Traducción en los Servicios Públicos
}

Wikis como herramientas de trabajo colaborativo complementario y desarrollo de recursos para la formación en traducción a nivel universitario: análisis retrospectivo Bianca Vitalaru. Página 6 de 47 
social/colaborativa y la creación de comunidades de prácticas en los dos tipos de estudios señalados (grado y postgrado) teniendo en cuenta los cursos académicos 20072008 y 2008-2009.

Finalmente, los estudios de Porto Requejo y Pena Díaz (2010) y Porto Requejo, Mancho Barés y Pena Díaz (2008) explican los beneficios de uso de las herramientas con principiantes en TIC debido a su fácil manejo y, en general, como complemento a la enseñanza presencial. Se insiste en la necesidad de incluir la actividad en la calificación final de la asignatura o algún incentivo externo para motivar la participación y el nivel de implicación del alumnado.

En la siguiente tabla se resumen los aspectos positivos o ventajas señalados por algunos autores:

\begin{tabular}{|c|c|c|}
\hline $\begin{array}{l}\text { Araujo Portugal (2014: 1-27). } \\
\text { Enseñanza de idiomas }\end{array}$ & $\begin{array}{l}\text { García Santiago (2016:152). } \\
\text { Traducción }\end{array}$ & $\begin{array}{l}\text { Vitalaru, Valero Garcés y Lázaro Gutiérrez } \\
\text { (2008). Elaboración de glosarios para } \\
\text { traductores. }\end{array}$ \\
\hline $\begin{array}{l}\text { - Desarrollo de la expresión escrita. } \\
\text { - } \\
\text { - Permiten compartir materiales. } \\
\text { proyecto. } \\
\text { - Fomentan el aprendizaje } \\
\text { autónomo. } \\
\text { - } \quad \text { Centran la atención en el proceso. } \\
\text { - Información sobre el desarrollo de } \\
\text { todo el proceso. } \\
\text { - } \quad \begin{array}{l}\text { Puede ampliarse o convertirse en } \\
\text { otro proyecto. }\end{array} \\
\text { - Información enriquecedora. } \\
\text { - Función usuarios: autores, editores } \\
\text { y colaboradores. } \\
\text { - Editar: contenidos y organización. } \\
\text { Complementario para asignatura } \\
\text { presencial. }\end{array}$ & $\begin{array}{l}\text { - Trabajo colaborativo. } \\
\text { - Revisión. } \\
\text { - Mejora aprendizaje } \\
\text { - Corrección errores ajenos. } \\
\text { - Proyectos de traducción. } \\
\text { - Flexibilidad del tiempo y } \\
\text { espacio. } \\
\text { - Ahorro de tiempo. } \\
\text { - Ayuda y nuevos } \\
\text { conocimientos. } \\
\text { - Compartición del } \\
\text { documento. } \\
\text { - Historial en tiempo real. }\end{array}$ & $\begin{array}{l}\text { - Participación activa. } \\
\text { - Comunicación. } \\
\text { - Habilidades de trabajo en grupo. } \\
\text { - Unidad de los grupos. } \\
\text { - Sentido de la responsabilidad } \\
\text { individual. } \\
\text { - Sentido crítico en la toma de decisiones. } \\
\text { - Aprendizaje de terminología } \\
\text { especializada. } \\
\text { - Concienciación sobre la complexidad } \\
\text { del trabajo profesional. } \\
\text { - Concienciación sobre la importancia de } \\
\text { una buena documentación. } \\
\text { - Práctica de la gestión de recursos. } \\
\text { - Orgullo de la autoría y edición del } \\
\text { material. }\end{array}$ \\
\hline
\end{tabular}

Tabla 1. Resumen aplicabilidad wikis en enseñanza de idiomas y traducción

En este trabajo nos centraremos en las herramientas wiki como instrumentos de fácil edición, que permiten escribir y construir contenido de manera colaborativa, monitorizar el trabajo de los participantes y finalmente, cuyo uso docente puede contribuir al desarrollo de una capacidad/habilidad importante, la del trabajo en grupo.

\section{Wikis en el máster de traducción e interpretación de la Universidad de Alcalá: construcción colaborativa como competencia del alumnado}

\subsection{Contexto}

El Máster Universitario en Comunicación Intercultural, Interpretación y Traducción en los Servicios Públicos de la Universidad de Alcalá se imparte como programa de postgrado oficial con desde el año 2006, en diferentes pares de lenguas. El máster, de 60 ECTS, se divide, desde el punto de vista académico, en 5 módulos con un total de 10 asignaturas (Folleto informativo, 2018-2019):

Wikis como herramientas de trabajo colaborativo complementario y desarrollo de recursos para la formación en traducción a nivel universitario: análisis retrospectivo Bianca Vitalaru. Página 7 de 47 


\begin{tabular}{|c|c|c|}
\hline Módulo y asignaturas & ECTS & Duración \\
\hline 1. Módulo sobre Comunicación Interlingüistica e Intercultural & 3 asignaturas & Octubre (online) \\
\hline Comunicación Interlingü ística & 5 ECTS & \\
\hline Comunicación Institucional con Población Extranjera (7 ECTS) & 7 ECTS & \\
\hline Técnicas y Recursos para la TISP (online y presencial) (6 ECTS) & 6 ECTS & \\
\hline $\begin{array}{l}\text { 2. Módulo sobre T\&I SANITARLA } \\
\text { (par de lenguas elegido) }\end{array}$ & & $\begin{array}{l}\text { Noviembre-diciembre } \\
\text { (presencial UAH) }\end{array}$ \\
\hline Interpretación en el ámbito sanitario & 5 ECTS & \\
\hline Traducción especializada: ámbito sanitario & 5 ECTS & \\
\hline $\begin{array}{l}\text { 3. Módulo sobre T\&I JURÍDICO-ADMINISTRATIVA (par de } \\
\text { lenguas elegido) }\end{array}$ & 3 asignaturas: & $\begin{array}{l}\text { Enero-febrero (presencial } \\
\text { UAH) }\end{array}$ \\
\hline Interpretación en el ámbito jurídico-administrativo & 8 ECTS & \\
\hline Traducción especializada: ámbito jurídico & 5 ECTS & \\
\hline Traducción especializada: ámbito administrativo & 5 ECTS & \\
\hline 4. Módulo: Prácticas en empresas e instituciones & 5 ECTS & $\begin{array}{l}\text { Marzo-junio (presencial } \\
\text { institución) }\end{array}$ \\
\hline 5. Módulo: Trabajo Fin de Máster & 9 ECTS & $\begin{array}{l}\text { Junio/ septiembre (entrega y } \\
\text { defensa) }\end{array}$ \\
\hline
\end{tabular}

Figura 1. Módulos y asignaturas ${ }^{8}$

En un análisis de las guías docentes ${ }^{9}$ por módulos observamos que las primeras tres asignaturas, que pertenecen al módulo 1, introductorio, se imparten principalmente online $^{10}$ y su objetivo es proporcionar conocimientos fundamentales sobre la comunicación intercultural e institucional necesarios antes de la T\&I en diferentes ámbitos, familiarizar al alumno al entorno de la TISP en España y en otros países y sus diferentes modalidades e introducir a las técnicas y recursos de la TISP.

En los siguientes dos módulos los alumnos practican intensivamente la T\&I en el ámbito sanitario y, respectivamente, en el ámbito jurídico-administrativo, centrándose en técnicas de traducción, resolución de problemas, análisis textual y uso de diferentes tipos de herramientas de documentación. Los módulos 4 y 5 consisten en Prácticas en instituciones y empresas y, respectivamente, elaboración de un trabajo de investigación. Sus objetivos son poner en práctica los conocimientos adquiridos y competencias desarrolladas en el resto de asignaturas e implican, en gran parte, las habilidades de documentación y trabajo autónomo.

Para complementar una parte de la formación en las asignaturas de Comunicación institucional con población extranjera $\mathrm{y}$, respectivamente, de Traducción especializada en los ámbitos sanitario y jurídico, se diseñaron diferentes tipos de actividades entre los cursos académicos 2007 y 2011. Dos profesores del máster, miembros de los grupos FITISPos-UAH y FILWIT, con experiencia en el uso de wikis en la docencia universitaria, eran responsables de esta actividad, uno de la especialidad de español-inglés y otro de la especialidad de español-rumano. En el caso de las actividades de elaboración de glosarios los profesores contaron con la colaboración de un profesor para cada una de las otras especialidades implicadas según el curso académico en cuestión (español-árabe, francés y polaco y, a partir del 2009, también para español-chino y ruso).

El primer curso académico en el que se implementó la herramienta wiki (20072008) se diseñaron dos tipos de actividades -redacción colaborativa y elaboración de glosarios-, reuniendo tres ámbitos distintos necesarios en diferentes asignaturas del

\footnotetext{
${ }^{8}$ http://www3.uah.es/traduccion

${ }^{9}$ https://www.uah.es/es/estudios/estudios-oficiales/masteres-universitarios/Comunicacion-InterculturalInterpretacion-y-Traduccion-en-los-Servicios-Publicos/\#planificacion-de-las-ensenanzas-y-profesoradoasignaturas-profesorado-competencias-guias-docentes-y-reglamento-del-trabajo-de-fin-de-master ${ }^{10}$ A excepción de la asignatura Técnicas y recursos para la TISP
}

Wikis como herramientas de trabajo colaborativo complementario y desarrollo de recursos para la formación en traducción a nivel universitario: análisis retrospectivo Bianca Vitalaru. Página 8 de 47 
título, todas con el objetivo de complementar la formación de los alumnos en ámbitos específicos de la T\&I: contexto general de la profesión, T\&I en el ámbito sanitario y T\&I en el ámbito jurídico-administrativo. Los objetivos eran tanto desarrollar la capacidad de trabajo colaborativo en los alumnos y de elaborar sus propios recursos de documentación, como evaluar la utilidad de estas herramientas en la docencia. Este objetivo era especialmente interesante desde el punto de vista de la creación de materiales válidos para los alumnos y los profesionales del campo de la TISP que contaban con recursos muy escasos en las siguientes combinaciones de lenguas: español-árabe/rumano/polaco y, más tarde, en español-ruso/chino.

En el diseño de las actividades iniciales partimos de la filosofía de Gannon y Fontainha, (2007: 1), que subrayaban la creación de "comunidades de práctica" y los valores que convierten el espacio virtual en una comunidad humana, más real: el sentido de conexión (sense of connectedness), la pasión compartida (shared passion), la profundización de conocimientos (deepening of knowledge) y el sentido del objetivo común (common sense of purpose) (Vitalaru, 2009). Además, éramos conscientes de que las tres características del trabajo en grupo en el espacio virtual de las wikis que permitían que estos valores tuvieran una aplicación práctica eran su versatilidad, la percepción como software social y la interacción continua entre los miembros del grupo. Por otro lado, pretendíamos que cada alumno tomara conciencia de la complejidad de su tarea como traductor, el nivel de responsabilidad requerido y la importancia de su implicación en la creación de sus propios recursos.

En los diferentes cursos académicos siguientes se ha trabajado con los alumnos de diferentes pares de lenguas según las especialidades que han tenido alumnos desde los inicios del programa (español-árabe/francés/inglés/polaco/rumano) y las nuevas que se han incorporado en 2009-2010 (español-chino y, respectivamente, español-ruso). Se ha trabajado particularmente en la elaboración de glosarios bilingües y multilingües de manera colaborativa aplicando lo aprendido en clase ya que la documentación en el ámbito temático de la traducción y la elaboración de glosarios (propios) son dos de las tareas fundamentales de todo traductor profesional. Las actividades y los diferentes cambios incorporados y planteamientos seguidos se describirán en los siguientes apartados, organizados según el tipo de actividad.

Finalmente, en retrospectiva, en el análisis actual tendremos en cuenta la función más general de las herramientas propuestas, es decir, lo que se denomina "construcción colaborativa" o "construcción colaborativa de conocimiento" (Anguita Martínez et al., 2010: 4-5; Occelli et al., 2013: 1) sobre la que se desarrollan las habilidades de trabajo en grupo y creación de sus propios recursos, ya indicadas. En trabajos anteriores (Vitalaru, Lázaro Gutiérrez y Valero Garcés, 2008 (como referencia general en las conclusiones) y Vitalaru, 2009 (como apartado principal)) preferimos referirnos exclusivamente a las tareas de redacción colaborativa como "construcción de contenido" para sugerir una capacidad con varias habilidades o una actividad con varias tareas. Sin embargo, en realidad, la función de construcción de contenido, en su sentido más general, se podría aplicar a cualquier tipo de contenido desde la redacción de contenido hasta la traducción o la elaboración de glosarios ya que implican un determinado proceso de trabajo. De hecho, consideramos que la 'construcción' consiste en un proceso con varios escalones que sus participantes deben subir para una determinada finalidad, que, una vez cumplida, demuestra el desarrollo de una capacidad específica. Por lo tanto, nos referiremos a ambos tipos de actividades como específicas para una capacidad de construcción que los participantes poseen o desarrollan.

Wikis como herramientas de trabajo colaborativo complementario y desarrollo de recursos para la formación en traducción a nivel universitario: análisis retrospectivo Bianca Vitalaru.

Página 9 de 47 


\subsection{Wikis como espacio de construcción colaborativa: redacción y comparación}

La actividad de construcción colaborativa utilizando el espacio wiki se utilizó durante tres cursos académicos distintos (entre 2007 y 2011) como parte de la asignatura Comunicación institucional con población extranjera (7 ECTS), impartida en el mes de octubre de manera online, antes de la parte presencial de noviembre a febrero. Se pretendía que los alumnos desarrollaran la capacidad de trabajar en grupo y fueran actores principales en su proceso de aprendizaje, particularmente en cuanto al desarrollo de las competencias específicas 2 y 3 de la Guía docente (2018-2019):

2. Adquirir los conceptos clave que intervienen en los ámbitos especializados de la TISP (sanitario/educativo/jurídico/administrativo).

3. Conocer el funcionamiento y procedimientos de los principales servicios e instituciones públicas de los ámbitos sanitario, educativo, jurídico-administrativo relevantes para la traducción e interpretación en las lenguas de la especialidad.

En la siguiente tabla se incluyen las tres actividades realizadas:

\begin{tabular}{|l|l|}
\hline Construcción y redacción de contenido relacionado con la T\&I & C. académico \\
\hline $\begin{array}{l}\text { Actividad Hablemos de T\&I } \\
\text { http://traduccionjuntos.wikispaces.com }\end{array}$ & $2007-2008$ \\
\hline $\begin{array}{l}\text { Actividad Hablemos de Traducción e Interpretación... } \\
\text { http://traduccionjuntos08-09.wikispaces.com }\end{array}$ & $2008-2009$ \\
\hline $\begin{array}{l}\text { Wiki Sistemas sanitarios. Actividad Sistemas sanitarios comparados } \\
\text { http://sistemas-sanitarios-uah.wikispaces.com/ }\end{array}$ & $2010-2011$ \\
\hline
\end{tabular}

Tabla 2. Resumen actividades de construcción colaborativa

La primera actividad de construcción y redacción colaborativa, diseñada e utilizada en el curso académico 2007-2008, era optativa y se centraba en la creación de una página sobre T\&I en general con información esencial y relevante seleccionada por los propios alumnos y tenía los siguientes objetivos específicos:

- Fomentar la participación activa de los alumnos en las actividades propuestas.

- Conseguir la comunicación y la unidad de los grupos formados.

- Crear una página sobre T\&I por y para los alumnos.

- Evaluar la utilidad de las herramientas wiki para el trabajo en grupo y para la elaboración de materiales útiles.

Los alumnos tenían que seguir unas pautas concretas para conseguir construir juntos un contexto relevante para completar los estudios presenciales para mejorar la calificación final de la asignatura. Las instrucciones eran: elegir un tema de la lista de trece temas propuestos y, en grupos de 5-6 personas, investigar, trabajar en grupo para seleccionar, sintetizar, redactar y aportar información a la wiki (tanto de los artículos propuestos en clase dentro de las diferentes asignaturas cursadas como de otros estimados oportunos), considerando su utilidad en función del tema elegido.

Wikis como herramientas de trabajo colaborativo complementario y desarrollo de recursos para la formación en traducción a nivel universitario: análisis retrospectivo Bianca Vitalaru. Página 10 de 47 
Algunos de los temas propuestos eran los siguientes (Lázaro Gutiérrez, Pena Díaz y Vitalaru, 2009: 9):

1. T\&I. Definiciones y perspectivas

2. Clasificación de los tipos de T\&I. Diferentes autores, diferentes puntos de vista.

3. Competencias del traductor y del intérprete. Requisitos y códigos de conducta.

4. Traductor jurado-Traductor jurídico-Traductor en los SP. Diferencias y estado de la cuestión en diferentes países.

5. Glosario monolingüe de términos sobre T\&I (en español)

6. Bibliografía general sobre T\&ISP.

En la Figura 2 podemos observar un ejemplo de la redacción de contenido para el tema 3 de la lista propuesta, para la cual se han empleado 25 ediciones:

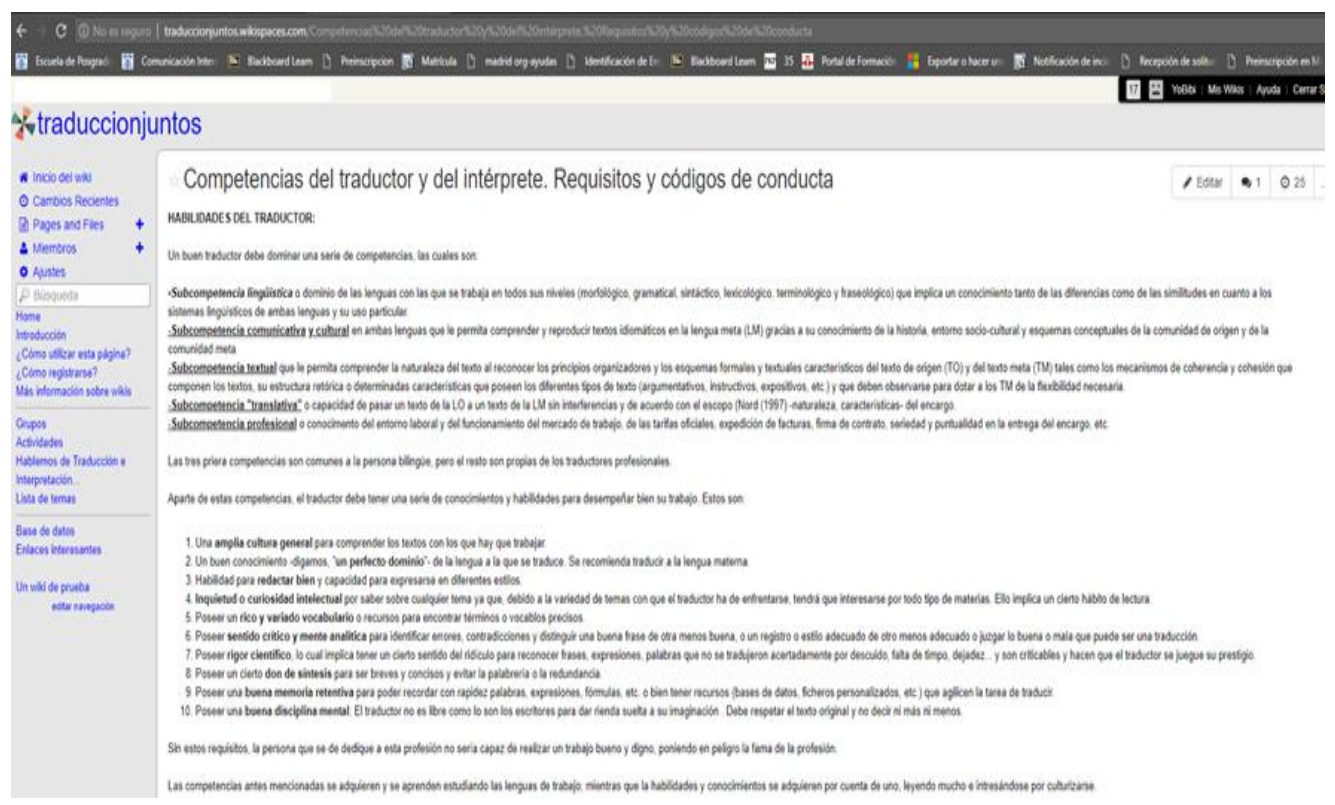

Figura 2. Redacción de contenido en 2007-2008

Teniendo en cuenta el éxito en cuanto al nivel de participación (50\% en el caso de los alumnos de rumano y del $80 \%$ en el caso de los de polaco) y las habilidades de síntesis y redacción que demostraron los alumnos, se utilizó la misma actividad en la misma asignatura el curso académico siguiente, 2008-2009 (segunda en la Tabla 2), esta vez obligatoria y adaptada a las necesidades identificadas en base a la experiencia del curso anterior. Por lo tanto, se realizaron cambios como la inclusión de instrucciones más precisas y contextuales al alumnado, tanto presencial como por email sobre la utilidad complementaria de la actividad, los diferentes criterios de evaluación, la importancia del esfuerzo individual para los resultados finales del grupo considerando que todos los miembros del grupo obtenían la misma nota, el papel del representante del grupo y la importancia de la originalidad y creatividad. Se utilizaron estrategias explicativas para conseguir una mayor comprensión escrita de lo que se esperaba del alumnado como "tratar a fondo un tema", "información esencial y relevante para todos vosotros/as y elegida por vosotros/as", "información que os parezca útil y oportuna en función del tema que hayáis elegido", "También se puede pedir ayuda/orientación a los compañeros de otros grupos si se necesita para tratar bien algún aspecto en concreto del tema elegido" e inclusivas como el uso de la primera persona del plural: "sobre el tema en el que todos/as

Wikis como herramientas de trabajo colaborativo complementario y desarrollo de recursos para la formación en traducción a nivel universitario: análisis retrospectivo Bianca Vitalaru. Página 11 de 47 
estamos interesados/as, ya que hemos decidido cursar estos estudios de traducción e interpretación”.

También se amplió la lista de propuestas de temas (Figura 3) para incluir la T\&I de los diferentes ámbitos como temas para desarrollar y bibliografía y recursos de documentación específicos para cada ámbito, un glosario de terminología sanitaria y más instrucciones específicas para los tres tipos de glosarios monolingües incluidos, cada uno de un ámbito tratado en diferentes asignaturas del máster (sanitario, administrativo y jurídico):

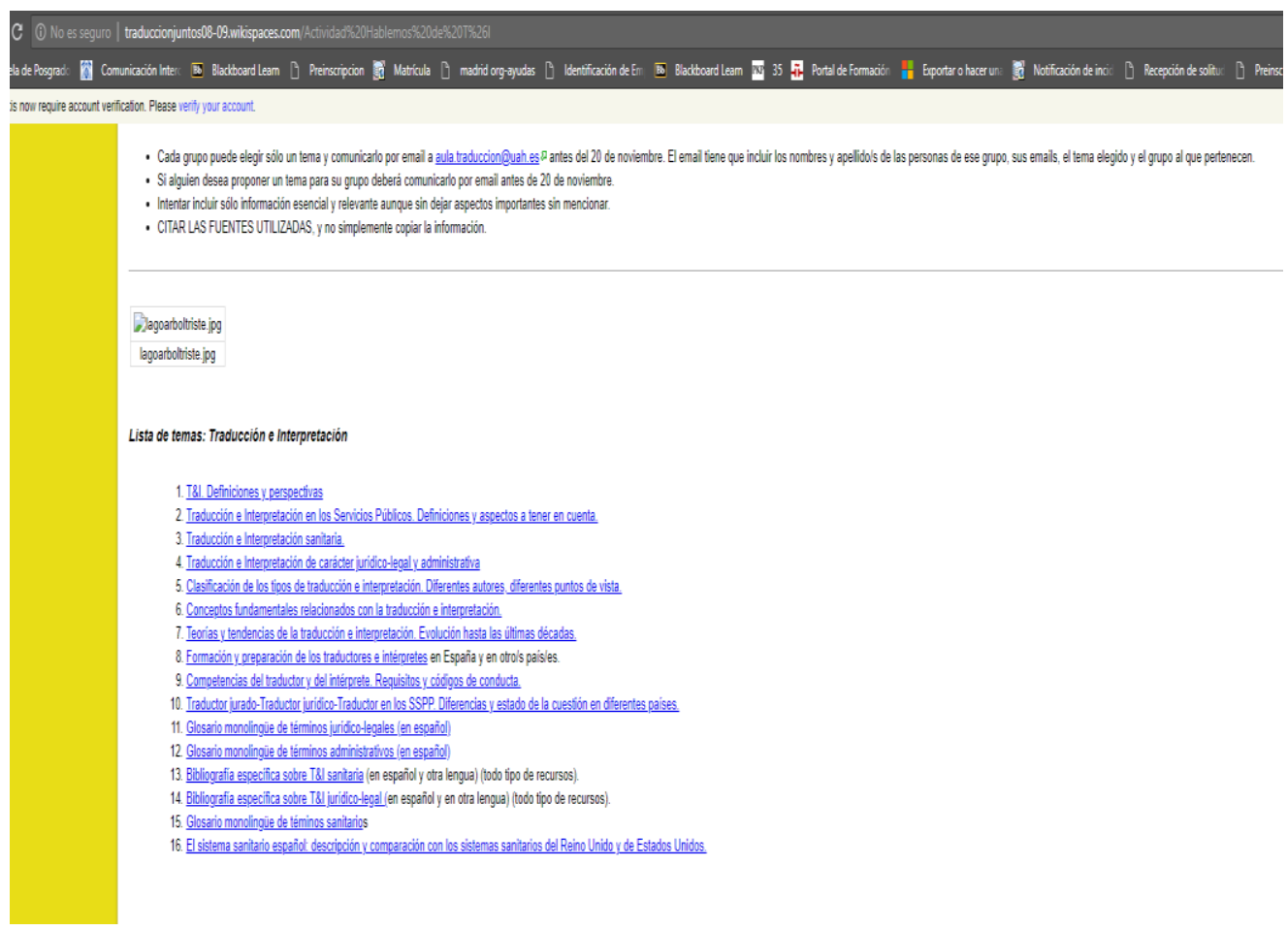

Figura 3. Temas propuestos en el curso 2008-2009

De esta manera, se pretendía centralizar la línea de trabajo y el esfuerzo del alumnado en los ámbitos más específicos del máster, ayudándoles a adquirir una base contextual y conceptual y ampliar los conocimientos proporcionados antes de la impartición de las asignaturas de Traducción y, respectivamente, de Interpretación, de cada ámbito. Por otro lado, se dejó bastante libertad en cuanto a la selección y organización de contenido por los propios grupos de trabajo formados.

Otro tema bastante específico incluido fue "El sistema sanitario español: descripción y comparación con los sistemas sanitarios del Reino Unido y de Estados Unidos". Su objetivo era introducir a la técnica de investigación comparativa de manera más específica y aplicada a lo que se podría considerar como base teórica de una parte de sus conocimientos de traducción de la asignatura Traducción especializada: ámbito sanitario (5 ECTS).

La última actividad señalada en el resumen de la Tabla 2 es la actividad de redacción de contenido del curso académico 2010-2011, cuyo objetivo también estaba relacionado con la asignatura de Traducción especializada: ámbito sanitario. En este caso, se ha decidido aprovechar el potencial del alumnado y canalizar su esfuerzo en la investigación y redacción conjunta de información que, según los informes del

Wikis como herramientas de trabajo colaborativo complementario y desarrollo de recursos para la formación en traducción a nivel universitario: análisis retrospectivo Bianca Vitalaru. Página 12 de 47 
profesorado, representaba una dificultad para gran parte del alumnado en la parte presencial de las asignaturas especializadas de Traducción e Interpretación. Se trataba, principalmente, de carencias formativas y trabajo autónomo de documentación del alumno sobre conceptos fundamentales e incluso sobre el funcionamiento de los diferentes sistemas implicados. Las sesiones teóricas específicas y la puesta en común de las clases introductorias eran, a veces, insuficientes teniendo en cuenta la multitud de países del habla en cuestión a los que se podía hacer referencia en el caso del árabe, del inglés o del francés, por ejemplo. Por lo tanto, esta vez, la actividad se centró en la descripción y comparación de aspectos concretos entre los sistemas de salud de España y de otros países de los pares de lenguas de impartición del máster: España, países árabes, China y otros países asiáticos, países de habla francesa (Francia y otros países de habla francesa), países de habla inglesa (EE.UU., Gran Bretaña, Irlanda, otros países de habla inglesa), Polonia, Rumanía, Rusia. En la siguiente figura se puede observar la organización planteada:

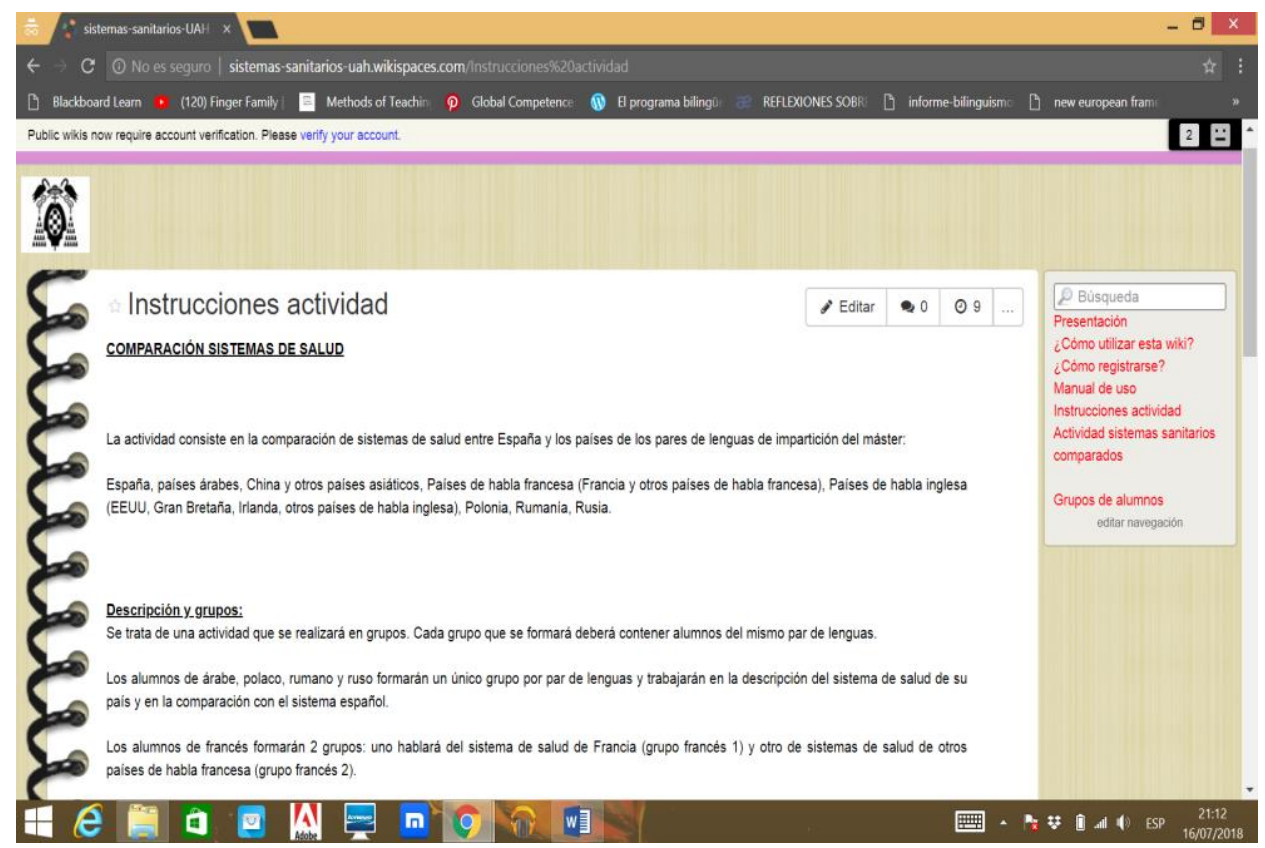

Figura 4. Actividad sistemas sanitarios comparados 2010-2011

Para evitar que no se cumplieran los objetivos para todas las lenguas del máster, es decir que todas las especialidades lingüísticas tuvieran la misma información contextual que los dos profesores de la tarea consideraban fundamental, esta vez se ha decidido incluir elementos específicos que los alumnos debían tener en cuenta tanto en la descripción como en la comparación en la realización de la actividad como descripción general del sistema, sistema de financiación, tipo de acceso, servicios y urgencias, entre otros. Se presentó como modelo ya estructurado, aunque sin información, el sistema español.

El sistema de evaluación empleado para este tipo de tarea ha sido la evaluación grupal, es decir, la misma calificación para todos los miembros de un mismo grupo. Desde nuestro punto de vista esta decisión era un factor importante para motivar al alumnado a implicarse para el beneficio de todos y a coordinarse con los compañeros. Finalmente, como partícipes directos en la selección de contenidos más relevantes y en

Wikis como herramientas de trabajo colaborativo complementario y desarrollo de recursos para la formación en traducción a nivel universitario: análisis retrospectivo Bianca Vitalaru. Página 13 de 47 
la toma de decisiones como parte de un grupo de trabajo, el aprendizaje iba a ser más ameno y práctico.

Si en 2007-2008 se trataba de una tarea optativa que representaba un punto extra sobre la calificación final de la asignatura, en los siguientes cursos académicos la nota de esta actividad representaba un $20 \%$ de la nota de la asignatura indicada, impartida antes de las clases presenciales. Los criterios de evaluación eran: calidad, cantidad, capacidad de síntesis y argumentación, capacidad de documentación, organización del contenido, coherencia y claridad, como reflejo de la comunicación de sus miembros. Los dos profesores que calificaron la actividad monitorizaban la realización de la misma contestando a dudas y revisando las aportaciones cada semana, pero teniendo en cuenta que lo que se tenía que evaluar era el producto final. En este caso, las aportaciones individuales eran reflejo de las decisiones de reparto y coordinación del grupo.

\subsection{Wikis como espacio de construcción colaborativa: elaboración de glosarios colaborativos}

Como ya hemos señalado, tal vez la función específica más valorada por los docentes es su versatilidad para el trabajo colaborativo, debido a su fácil manejo y edición. El trabajo colaborativo en sí puede tener diferentes finalidades en función del tema que nos interesa y de los objetivos propuestos a corto o a largo plazo. En este caso, las herramientas se han utilizado como instrumento fundamental para que los alumnos construyeran glosarios de utilidad para sus clases y su futuro profesional de manera colaborativa y, a la vez, desarrollaran dos habilidades: la de saber trabajar en grupo de manera eficaz y la de crear sus propios recursos con la terminología aprendida como parte de su proceso de aprendizaje. Estas habilidades formaban parte de dos competencias fundamentales de las asignaturas de traducción especializada ${ }^{11}$ del máster:

- Competencia genérica: "4. Adquirir la capacidad para la planificación y gestión del tiempo en las tareas propias de traducción e interpretación en el ámbito de los servicios públicos”.

- Competencia específica: “4. Competencia documental basada en el dominio y aplicación de técnicas y estrategias adecuadas de documentación, así como en criterios de selección y evaluación de herramientas de utilidad para facilitar el trabajo" (Guía docente Traducción especializada: ámbito jurídico, 2018-2019).

Según Lázaro Gutiérrez, Pena Díaz y Vitalaru (2010: 4), la utilidad de la elaboración de glosarios como actividad formativa se debe a sus dos objetivos principales: aprendizaje de vocabulario especializado, que es esencial cuando se aprenden segundas lenguas para fines específicos, y aplicabilidad como recurso que permite realizar traducciones tanto durante el periodo formativo como en la vida profesional y que puede ser ampliado y actualizado con facilidad. En cambio, Vitalaru (2009: 2) y Vitalaru, Valero Garcés y Lázaro Gutiérrez (2008: 597) subrayan la utilidad del trabajo colaborativo para la elaboración de glosarios ad hoc especialmente para

\footnotetext{
${ }^{11}$ Traducción especializada en el ámbito sanitario; Traducción especializada en el ámbito administrativo y Traducción especializada en el ámbito jurídico.
}

Wikis como herramientas de trabajo colaborativo complementario y desarrollo de recursos para la formación en traducción a nivel universitario: análisis retrospectivo Bianca Vitalaru. Página 14 de 47 
alumnos y traductores de combinaciones lingüísticas que cuentan con pocos recursos especializados bilingüies.

En el siguiente apartado describiremos las actividades diseñadas e utilizadas como complementarias durante los meses presenciales de las asignaturas de Traducción especializada, así como los cambios de un curso académico a otro.

\subsubsection{Elaboración de glosarios bilingües}

Las actividades centradas en la elaboración de glosarios bilingües en el Máster TISP en espacios colaborativos wiki se implementaron en los cursos 2007-2008 y 20082009. A partir de las tareas propuestas se generaron tres glosarios (Tabla 3):

\begin{tabular}{|l|l|}
\hline Glosarios bilingües & C. académico \\
\hline $\begin{array}{l}\text { Actividad mini glosarios sanitarios bilingües } \\
\text { http://traduccionsanitaria.wikispaces.com }\end{array}$ & $2007-2008$ \\
$\begin{array}{l}\text { Actividad mini glosarios jurídicos bilingües } \\
\text { http://traduccionjuridicoadministrativa.wikispaces.com }\end{array}$ & $2008-2009$ \\
\hline $\begin{array}{l}\text { Glosarios bilingües jurídicos de derecho penal y laboral } \\
\text { http://glosarios-juridicos-bilingues.wikispaces.com }\end{array}$ & \\
\hline
\end{tabular}

Tabla 3. Glosarios bilingües

La finalidad específica perseguida en las dos actividades del curso académico 2007-2008 era la elaboración de pequeños glosarios especializados bilingües de utilidad para los alumnos en formación y para los profesionales del campo de la TISP mediante el trabajo colaborativo. Los alumnos debían elaborar lo que hemos denominado "mini glosarios" sanitarios y jurídicos, en equipos formados por dos grupos: terminólogos (3-4 personas) y traductores (3-4 personas) de la misma combinación de lenguas (Vitalaru, Valero-Garcés y Lázaro Gutiérrez, 2008: 598). A diferencia de la primera actividad de redacción colaborativa, en la que la asignación de las diferentes tareas en la organización interna del grupo era competencia de los propios miembros del grupo, en estas dos actividades cada parte importante del equipo (terminólogos, traductores), y, seguidamente, cada miembro del grupo, tenía asignadas tareas concretas orientadas a la tarea principal del grupo; por ejemplo, recopilación de corpus y selección de terminología por los terminólogos y compleción de ficha terminológica y traducción por los traductores (Tabla 4):

Wikis como herramientas de trabajo colaborativo complementario y desarrollo de recursos para la formación en traducción a nivel universitario: análisis retrospectivo Bianca Vitalaru. Página 15 de 47 


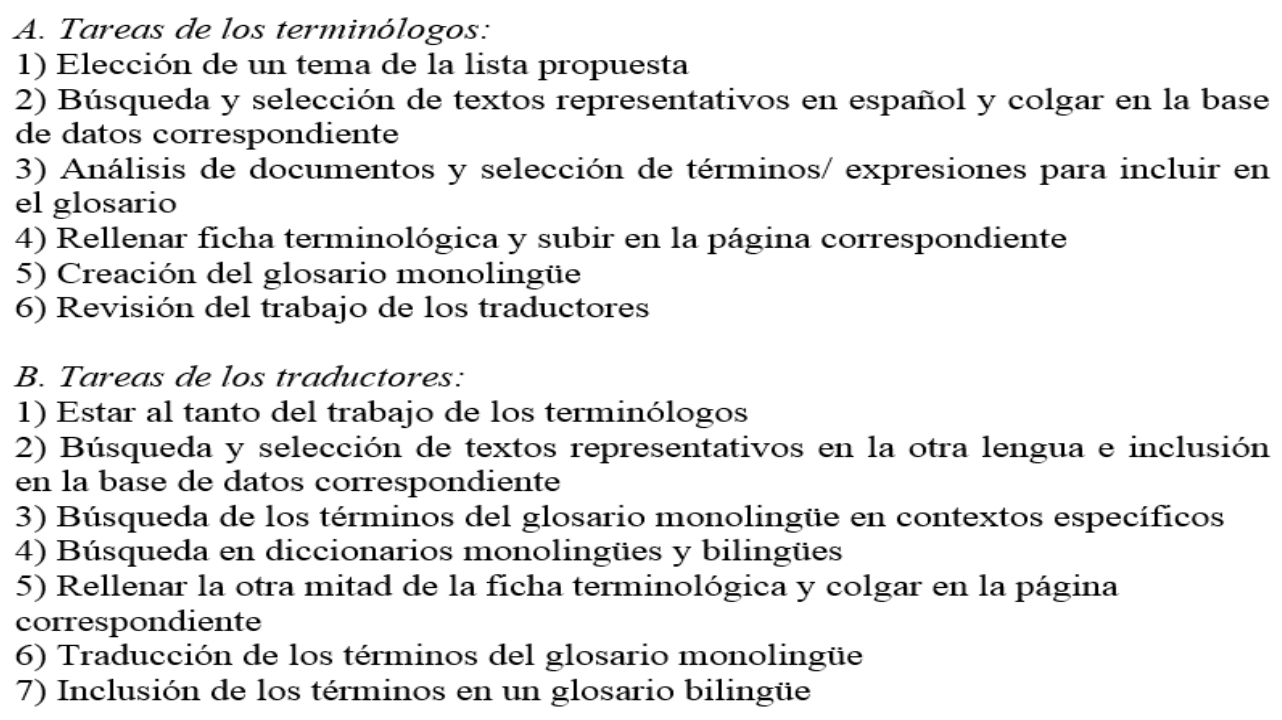

Tabla 4. Tareas de los terminólogos y traductores. Vitalaru, Valero-Garcés y Lázaro Gutiérrez (2008: 598-599)

Es importante destacar que los dos grupos que formaban un equipo jugaban papeles fundamentales dentro del mismo y la colaboración constante y coordinación de los grupos era primordial para asegurar el éxito del equipo, ya que los miembros del equipo obtenían la misma calificación final. Se proponía una lista de temas dentro de cada ámbito, aunque los alumnos también podían proponer otros temas. Mencionamos los temas de cada ámbito (Vitalaru, Valero-Garcés y Lázaro Gutiérrez, 2008: 599; Lázaro Gutiérrez, Pena Díaz y Vitalaru, 2009: 6):

\begin{tabular}{|l|c|}
\hline - Sanitario: & - Jurídico-administrativo: TERMINOLOGÍA \\
\hline 1. Enfermedades más comunes & 1. Conceptos jurídicos fundamentales \\
2. Enfermedades mentales & 2. Derecho penal \\
3. Fobias & 3. Derecho laboral \\
4. Pediatría & 4. Extranjería \\
5. SIDA-VIH & 5. Derecho civil \\
6. Violencia doméstica & \\
\hline
\end{tabular}

Tabla 5. Temas propuestos glosarios bilingües 2007-2008. Vitalaru, Valero-Garcés y Lázaro Gutiérrez (2008: 599)

En el curso académico 2008-2009 se propuso únicamente la actividad de elaboración de glosarios bilingües en el módulo jurídico en dos ámbitos específicos que se trabajaban en dos de las asignaturas del máster (Traducción especializada: ámbito jurídico e Interpretación en el ámbito jurídico-administrativo): laboral y penal. Las características de la actividad han cambiado con respecto al curso anterior. En primer lugar, aunque seguía tratándose de una actividad de grupo a nivel de especialidad lingüística, cada alumno tenía que contribuir a la construcción conjunta de un glosario monolingüe en español (del ámbito penal o laboral), de utilidad para todas las especialidades del máster y de un glosario bilingüe en su combinación de lenguas. Esta vez, los alumnos ya no tenían que formar equipos con grupos de terminólogos y traductores, sino practicar las dos tareas implicadas. Es decir, cada alumno tenía que

Wikis como herramientas de trabajo colaborativo complementario y desarrollo de recursos para la formación en traducción a nivel universitario: análisis retrospectivo Bianca Vitalaru. Página 16 de 47 
actuar como terminólogo en la primera parte del trabajo y como traductor en la segunda parte sin tener que coordinarse con compañeros, excepto en cuanto a la selección de términos y sin contar con revisiones posteriores del trabajo de cada uno. Eso implicaba que la segunda fase del trabajo dependía de un buen trabajo de selección en la primera fase. Las instrucciones que los alumnos recibieron sobre las fases de trabajo eran las siguientes:

1) Proponer 20 términos de uno de los ámbitos propuestos. Algunas instrucciones específicas de esta fase eran:

"Es importante tener cuidado en la elección de términos. Después de realizar este módulo debéis de tener bastante claros los conceptos dentro de su rama jurídica (en este caso derecho penal y laboral). Deberían ser conceptos más comunes o más utilizados, los que suelen plantear problemas a la hora de traducir, etc."

2) Incluirlos en la lista de términos en español para que otra persona no eligiera los mismos términos (orden alfabético). En la siguiente figura se observa el espacio creado:

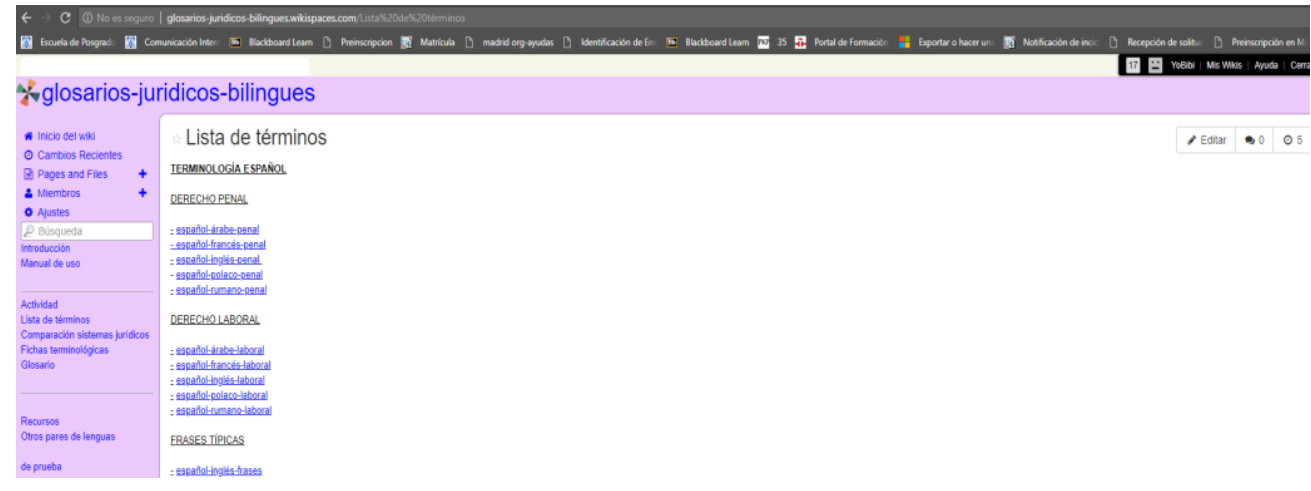

Figura 5. Espacio para lista de términos

Para evitar que se trabajaran los mismos términos por diferentes alumnos se estableció un periodo para la inclusión de términos en el glosario monolingüe que todos los participantes tenía que revisar antes de empezar la parte terminológica. La rapidez en cuanto a esta primera parte y la consulta del trabajo previo de los compañeros eran importantes ya que cada término se tenía que incluir una sola vez. Para esta actividad los profesores tuvieron en cuenta el número total de alumnos en cada especialidad, de modo que no se pretendía generar glosarios con el mismo número de términos en todas las especialidades.

3) Rellenar una ficha terminológica, con los términos propuestos inicialmente por cada alumno. Era obligatorio cumplimentar las columnas de las dos partes (en español y en la otra lengua) como en el ejemplo de la Figura 6, que pertenece a la ficha bilingüe del ámbito penal en español-árabe.

Wikis como herramientas de trabajo colaborativo complementario y desarrollo de recursos para la formación en traducción a nivel universitario: análisis retrospectivo Bianca Vitalaru. Página 17 de 47 


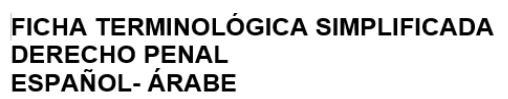

\begin{tabular}{|c|c|c|c|c|c|c|c|c|}
\hline TÉRMINO & DEFINICIÓN & CONTEXTO & FUENTE & TRADUCCIÓN & DEFINICIÓN & CONTEXTO & FUENTE & $\begin{array}{l}\text { OBSERVAC } \\
\text { IONES }\end{array}$ \\
\hline الاصطلاح & التعريف & السياق النصي & المصدر & 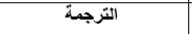 & التعريف & السباق النصبي & المصدر & ملاحظات \\
\hline $\begin{array}{l}\text { Auto de } \\
\text { detención }\end{array}$ & $\begin{array}{l}\text { 1. (Auto) Forma } \\
\text { de resolución } \\
\text { judicial, fundada, } \\
\text { que decide } \\
\text { cuestiones } \\
\text { secundarias, } \\
\text { previas, } \\
\text { incidentales o de } \\
\text { ejecución, para } \\
\text { las que no se } \\
\text { requiere } \\
\text { sentencia. } \\
\text { 2. (Auto) Conjunto } \\
\text { de actuaciones o } \\
\text { piezas de un } \\
\text { procedimiento } \\
\text { judicial } \\
\text { 1. (Detención) } \\
\text { Delito en que } \\
\text { incurre quien, sin }\end{array}$ & $\begin{array}{l}\text { Auto de } \\
\text { detención } \\
\text { dictado a } \\
\text { Augusto } \\
\text { Pinochet. } \\
\\
\text { Procedimiento } \\
\text { : SUMARIO } \\
\text { 19/97 P.S. } \\
\text { TERRORISM } \\
\text { OY } \\
\text { GENOCIDIO } \\
\text { JUZGADO } \\
\text { CENTRAL DE } \\
\text { INSTRUCCIÓ } \\
\text { N } \\
\text { NÚMERO } \\
\text { CINCO } \\
\text { AUDIENCIA } \\
\text { NACIONAI }\end{array}$ & $\begin{array}{l}\text { Definición: } \\
\text { http://busco } \\
\text { n.rae.es/dr } \\
\text { ael/SrviltCo } \\
\text { nsulta?TIP } \\
\text { O_BUS=3\& } \\
\text { LEMA=auto } \\
\text { http://busco } \\
\text { n.rae.es/dr } \\
\text { ael/SrviltCo } \\
\text { nsulta?TIP } \\
\text { O_BUS=3\& } \\
\text { LEMA=dete } \\
\text { nción } \\
\text { Contexto: } \\
\text { http://www. } \\
\text { analitica.co }\end{array}$ & قر قرار اعتقال. & 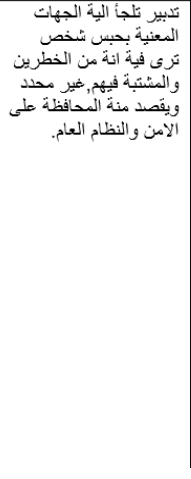 & 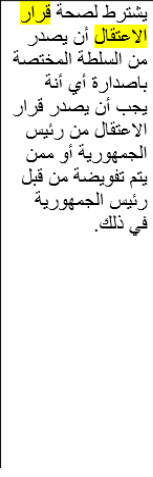 & \begin{tabular}{l}
\multicolumn{1}{c}{ : } \\
http://www. \\
maat- \\
law.org/Gif/e \\
sdarat/shoro \\
t\%20se7at\% \\
$202 \mid \% 20 \mathrm{e} 3 \mathrm{t}$ \\
ekal.pdf \\
\multicolumn{1}{|}{} \\
http://www. \\
maat- \\
law.org/Gif/e \\
sdarat/shoro \\
t\%20se7at\% \\
$202 \mid \% 20 \mathrm{e} 3 \mathrm{t}$ \\
ekal.pdf
\end{tabular} & 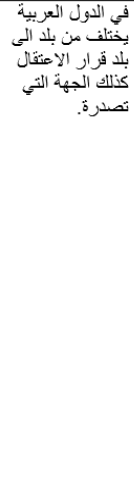 \\
\hline
\end{tabular}

Figura 6. Ejemplo de ficha terminológica bilingüe

En este caso, los alumnos recibieron recomendaciones más específicas como:

"Es importante tener mucho cuidado en la selección de contextos. Tienen que ser claros con respecto al significado en diferentes situaciones. En la parte de traducción también hay que tener en cuenta los posibles significados del concepto".

4) Incluir los términos en el glosario bilingüe en el apartado correspondiente por orden alfabético.

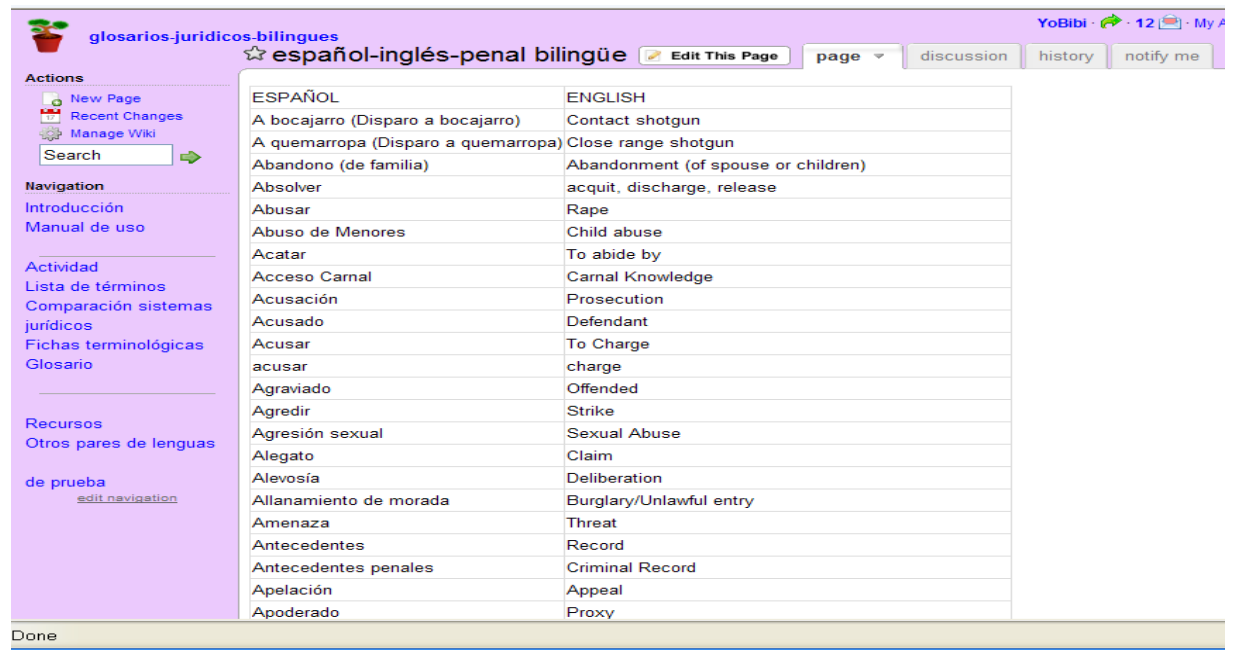

Figura 7. Ejemplo: glosario jurídico bilingüe 2008-2009

Por último, cabe señalar que el sistema de evaluación utilizado tuvo características similares en los dos cursos académicos analizados. En primer lugar, los dos profesores responsables de esta actividad, de las especialidades de español-inglés y, respectivamente, de español-rumano, colaboraron con un profesor de cada una de las

Wikis como herramientas de trabajo colaborativo complementario y desarrollo de recursos para la formación en traducción a nivel universitario: análisis retrospectivo Bianca Vitalaru. 
otras especialidades lingüísticas para calificar la parte de traducción ${ }^{12}$. En segundo lugar, en ambos cursos se tuvieron en cuenta los mismos parámetros de evaluación:

a) Parte terminológica/ Capacidad de documentación:

- Selección del término.

- Idoneidad y precisión de la información.

- Calidad (tipo de fuentes, inclusión de definiciones y contexto).

- Organización del contenido.

- Coherencia y uniformidad de contenido, estilo y formato.

b) Traducción/Capacidad traductora:

- Precisión en el uso de la técnica de traducción.

- Opciones, comentarios y/o contexto.

En cuanto a las diferencias apreciadas, destacan el tipo de actividad (optativa/obligatoria) y la contabilización de la actividad en la calificación final de la asignatura. En el caso de la actividad de 2007-2008, optativa, la nota representaba un $10 \%$ extra sobre la nota final de la asignatura y la evaluación era grupal, lo que implicaba una única calificación para todos los miembros del mismo equipo. En cambio, en el caso de la actividad de 2008-2009, obligatoria, la nota representaba un $10 \%$ de la calificación de la asignatura y la evaluación era individual. De este modo, se evaluaba cualitativamente la aportación de cada alumno teniendo en cuenta los mismos aspectos mencionados. En ambos cursos, la calificación de la actividad (grupal o individual) era la media resultada de la nota obtenida para cada uno de los dos parámetros principales (documentación y traducción).

\subsubsection{Elaboración de glosarios multilingües}

Otro tipo de actividad similar a la elaboración de glosarios bilingües era la elaboración de glosarios multilingües, realizada en la actividad del módulo sanitario de los cursos académicos 2008-2009 y 2009-2010. Concretamente, se pretendía elaborar dos glosarios multilingües del ámbito sanitario con la misma terminología en las diferentes lenguas impartidas en el programa en el curso académico en cuestión: un glosario sanitario multilingüe general en español-árabe-francés-inglés-polaco-rumano y un glosario multilingüe de enfermedades más comunes en español-árabe-chino-inglésrumano-ruso. Los detalles sobre los glosarios generados se mencionan en la Tabla 6:

\begin{tabular}{|l|l|}
\hline Glosarios multilingües (ámbito sanitario) & C. académico \\
\hline $\begin{array}{l}\text { Glosario sanitario multilingüe general en español-árabe-francés-inglés- } \\
\text { polaco-rumano } \\
\text { http://glosario-sanitario-multilingue.wikispaces.com }\end{array}$ & 2008-2009 \\
\hline $\begin{array}{l}\text { Glosario multilingüe de enfermedades más comunes en español-árabe- } \\
\text { chino-inglés-rumano-ruso } \\
\text { http://glosario-enfermedades-multilingue.wikispaces.com }\end{array}$ & $2009-2010$ \\
\hline
\end{tabular}

Tabla 6. Glosarios multilingües ámbito sanitario

Los alumnos recibieron instrucciones específicas y detalladas con respecto al proceso de elaboración y a la importancia de la organización y funcionamiento como

\footnotetext{
${ }^{12}$ De las especialidades de árabe, francés y polaco
}

Wikis como herramientas de trabajo colaborativo complementario y desarrollo de recursos para la formación en traducción a nivel universitario: análisis retrospectivo Bianca Vitalaru. Página 19 de 47 
grupo. Se les explicó que la coordinación y planificación como grupo era primordial y que las tareas individuales de sus miembros dependían de la organización interna de cada grupo.

Las instrucciones generales para la primera actividad eran las siguientes:

1. Formar grupos de 4-5 personas por lengua.

2. Cada miembro del grupo: realizar tareas de terminólogos (buscar contextos, completar fichas terminológicas, etc.) y de traductores.

3. Cada grupo:

- proponer 50 términos de un tema del ámbito sanitario (de la lista propuesta o proponer otros).

- incluirlos en un glosario monolingüe.

- Trabajar, según las instrucciones, para elaborar un glosario multilingüe sobre diferentes temas concretas del ámbito sanitario.

Tabla 7. Instrucciones generales glosario 2008-2009

Para una mejor claridad y para facilitar la organización de tareas se especificaban las tareas de los grupos y la responsabilidad de los miembros de manera expresa:
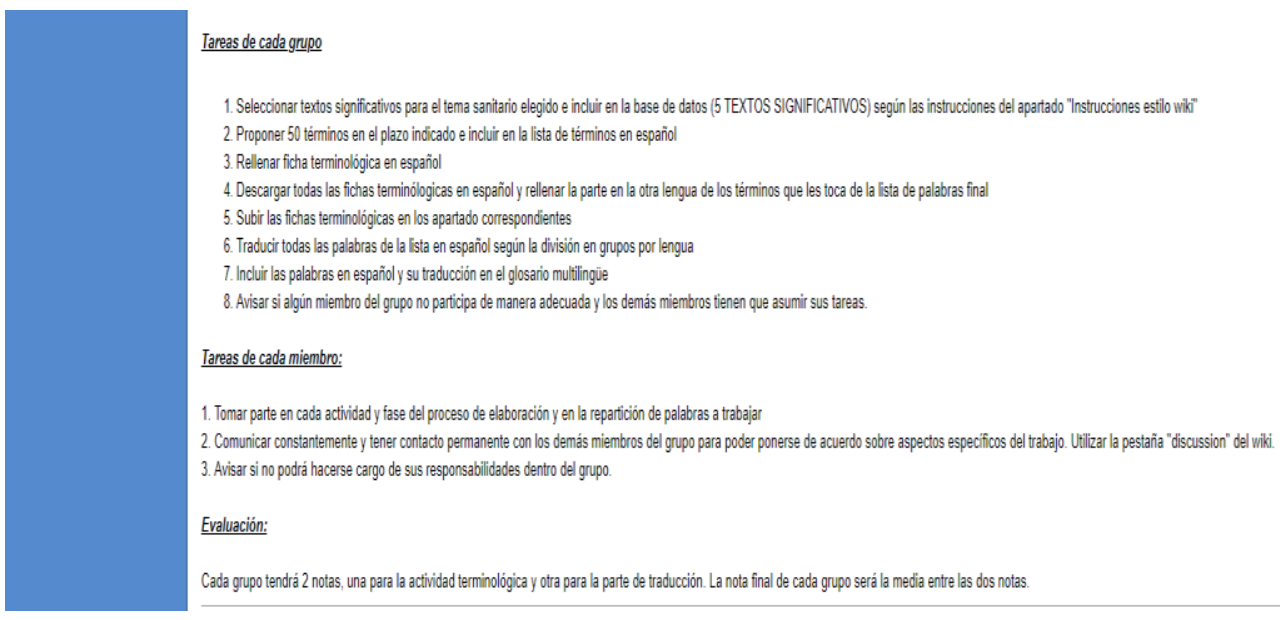

Figura 8. Instrucciones específicas sobre tareas y responsabilidades 2008-2009

El número de palabras que tenían que traducir los grupos de árabe, polaco, rumano, francés y árabe era mayor ya que contaban con menos alumnos (4, 4, 8 y 12) que el grupo de español-inglés, que contaba con más alumnos (23); por lo tanto, los primeros grupos contaron con más plazo para realizar la tarea.

La lista de temas finalmente se materializó en un glosario monolingüe con los siguientes temas: embarazo, enfermedades más comunes, enfermedades mentales, instrumentos médicos, pediatría, personal médico y organización del hospital, SIDAVIH, síntomas y efectos, tipos de documentos y expresiones típicas, tratamientos e intervenciones (tipos) y violencia doméstica (Figura 9):

Wikis como herramientas de trabajo colaborativo complementario y desarrollo de recursos para la formación en traducción a nivel universitario: análisis retrospectivo Bianca Vitalaru. Página 20 de 47 


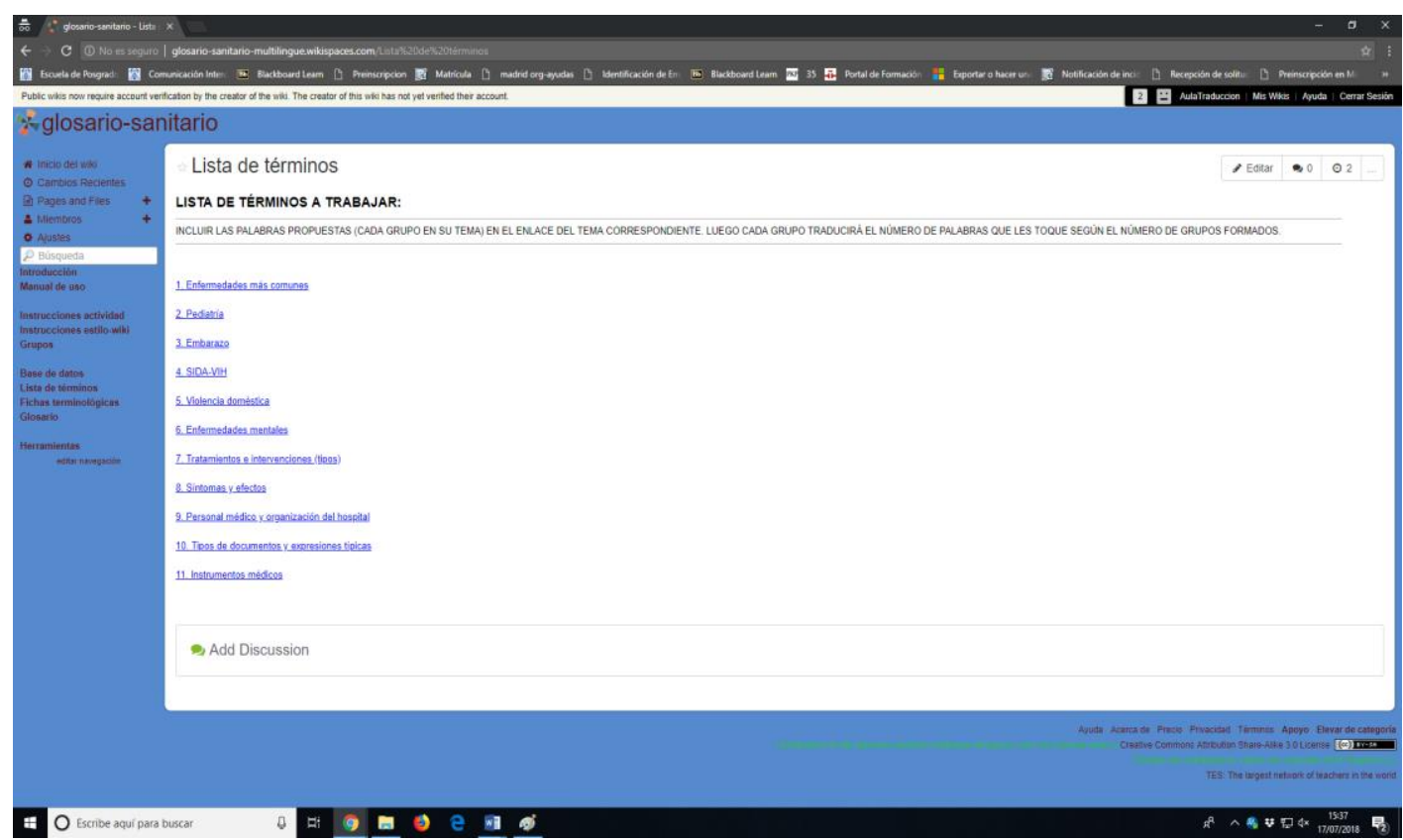

Figura 9. Lista de temas glosario sanitario monolingüe 2008-2009

La siguiente figura incluye un ejemplo de términos incluidos por los alumnos en uno de los glosarios monolingües:

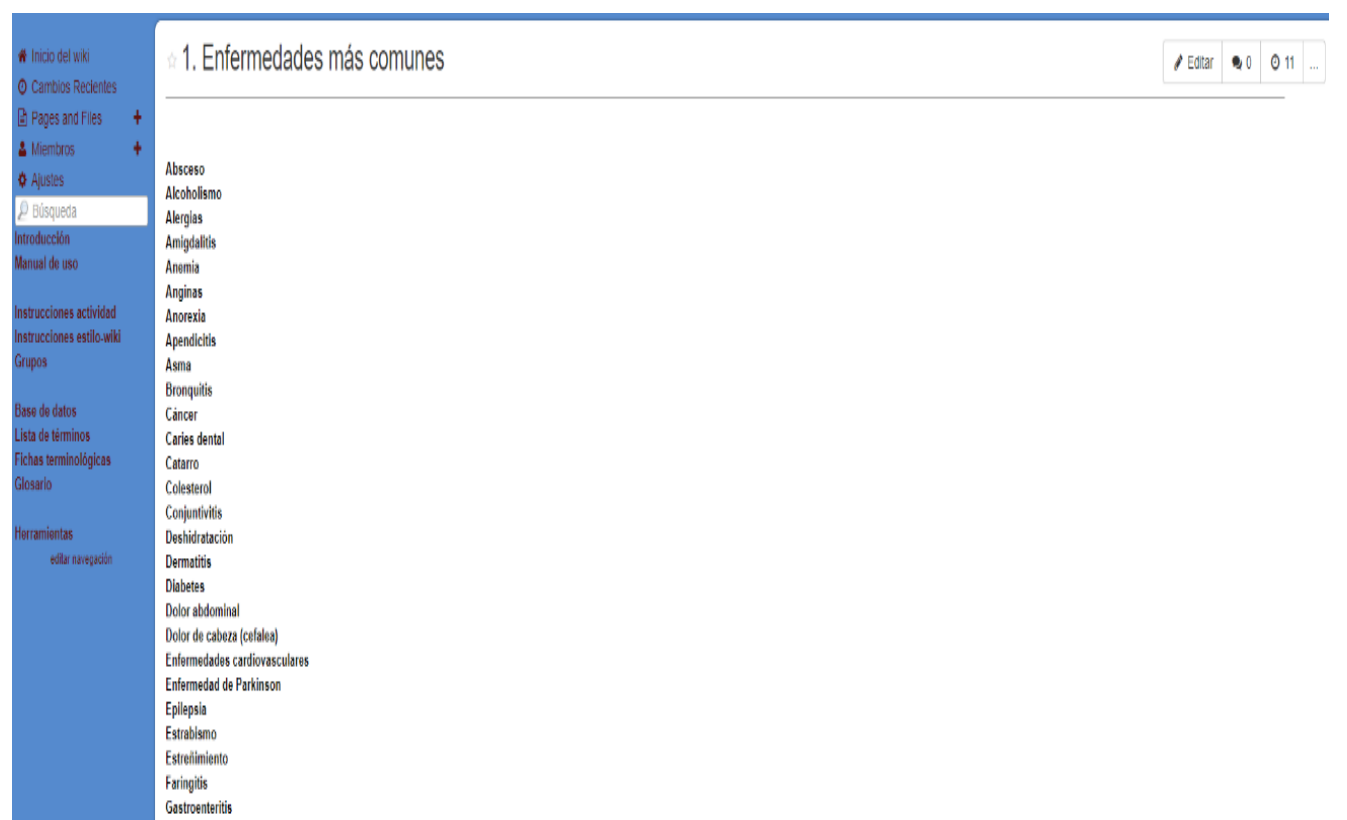

Figura 10. Ejemplo de términos incluidos glosario sanitario monolingüe 2008-2009

Cabe señalar que, en el caso de esta actividad, la participación de todos los miembros del grupo era fundamental, ya que su éxito dependía de la participación de todos, de modo que tenían que colaborar constantemente durante el proceso de elaboración. A su vez, cada miembro del grupo tenía un papel activo fundamental, teniendo que participar para el beneficio del grupo. Por lo tanto, el proceso de elaboración, aunque exitoso, fue bastante laborioso e implicaba la interdependencia de los grupos especialmente para la parte terminológica en español.

Wikis como herramientas de trabajo colaborativo complementario y desarrollo de recursos para la formación en traducción a nivel universitario: análisis retrospectivo Bianca Vitalaru. Página 21 de 47 
En el curso académico 2009-2010 se realizó un cambio importante para simplificar la primera parte (terminológica) de elaboración del glosario que, en el curso académico anterior, dependía de la participación inicial de todos los grupos y que era bastante complicada. Por lo tanto, en este curso académico el proceso de recopilación y propuesta de terminología para el glosario final fue realizado por los dos profesores responsables de la actividad. De este modo, para poder elaborar el glosario multilingüe, los alumnos de todos los grupos recibieron el glosario de enfermedades en español. Se trataba, esta vez, de un glosario más específico dentro del ámbito sanitario, que incluía terminología de los diferentes tipos de enfermedades, teniendo en cuenta un número ya establecido de términos (Tabla 8):

\begin{tabular}{|l|l|}
\hline Glosario de enfermedades del cerebro: & 27 términos \\
\hline Glosario de enfermedades del corazón: & 44 términos \\
\hline Glosario de enfermedades digestivas: & 23 términos \\
\hline Glosario de enfermedades hepáticas: & 50 términos \\
\hline Glosario de enfermedades infecciosas: & 67 términos \\
\hline Glosario de enfermedades mentales: & 46 términos \\
\hline Glosario de enfermedades óseas: & 28 términos \\
\hline Glosario de enfermedades pulmonares/respiratorias: & 29 términos \\
\hline Glosario de enfermedades renales: & 37 términos \\
\hline Glosario de otras enfermedades: & 150 términos. \\
\hline
\end{tabular}

Tabla 8. Tipos de enfermedades y términos propuestos 2009-2010

El procedimiento seguido en el reparto de los términos dentro de los grupos y las instrucciones de trabajo eran las mismas del curso académico anterior y tenían los mismos objetivos: fomentar el trabajo en grupo, incluir a los alumnos en su proceso de aprendizaje mediante el trabajo colaborativo y evaluar la utilidad de la herramienta. Además, en base a la experiencia anterior, incorporamos cambios para fomentar la participación activa de los alumnos de todos los grupos. De ahí la inclusión de un glosario monolingüe y la obligatoriedad de que cada grupo tuviera un delegadocoordinador para estar en contacto y facilitar la comunicación con los profesores responsables de esta tarea.

En cuanto a la evaluación de ambas actividades, al igual que en el caso de los glosarios bilingües de 2007-2008, se trataba de una evaluación grupal que tenía en cuenta los criterios ya indicados en el apartado 3.3.1. A diferencia del curso 2007-2008, la participación era obligatoria y la nota representaba un 10\% (máximo de 1 punto) de la calificación final de la asignatura Traducción especializada: ámbito sanitario.

\section{Resultados}

En un análisis inicial de los resultados obtenidos (Vitalaru, 2009) considerábamos que los resultados obtenidos de las actividades de trabajo colaborativo podían clasificarse en tres categorías: resultados materiales, resultados estadísticos y resultados intrínsecos. En este trabajo seguiremos una clasificación similar, pero adaptada a la visión retrospectiva y a los objetivos del presente análisis. A continuación, describiremos los aspectos observados desde tres puntos de vista: resultados materiales, nivel de participación y desarrollo de habilidades específicas.

Wikis como herramientas de trabajo colaborativo complementario y desarrollo de recursos para la formación en traducción a nivel universitario: análisis retrospectivo Bianca Vitalaru. Página 22 de 47 


\subsection{Resultados de las actividades de redacción colaborativa}

\subsubsection{Resultados materiales}

Los resultados materiales de la primera actividad de redacción colaborativa consistían en la elaboración de varias páginas Web con contenido informativo útil tanto en cuanto a la información sobre los conceptos esenciales dentro del mundo de la T\&I profesional, como desde el punto de vista de la propuesta de recursos seleccionados por los alumnos en función de su utilidad para el trabajo a desempeñar: traducción de documentos de diferentes ámbitos (educativo, sanitario, administrativo, jurídico) o diferentes situaciones de interpretación basadas en el uso de esta terminología.

Los temas elegidos de la lista propuesta en los cursos académicos 2007-2008 (como actividad optativa) y 2008-2009 (como actividad obligatoria) se pueden ver en las Tablas 9 y 10:

\begin{tabular}{|c|c|}
\hline Grupo 4: Rumano & Tema 4: Conceptos fundamentales relacionados con la traducción e interpretación. \\
\hline Grupo 7: Inglés & Tema 7: Competencias del traductor y del intérprete. Requisitos y códigos de conducta. \\
\hline Grupo 9: Francés & Tema 9: Glosario monolingüe de términos sobre T\&I (en español) \\
\hline Grupo 10: Polaco & Tema 10: Glosario monolingüe de términos jurílicos (en español) \\
\hline Grupo 11: Francés & Tema 11: Glosario monolingüe de términos administrativos (en español) \\
\hline Grupo 12: Inglés & Tema 12: Bibliografia general sobre T\&I en los Servicios Públicos \\
\hline
\end{tabular}

Tabla 9. Temas tratados en la actividad de redacción colaborativa 2007-2008

\begin{tabular}{|l|l|}
\hline Grupo 1: Árabe & Tema 1: T\&I. Definiciones y perspectivas \\
\hline Grupo 3: Rumano & Tema 3: Traducción e Interpretación Sanitaria \\
\hline Grupo 6: Rumano & Tema 6: Conceptos fundamentales relacionados con la traducción e interpretación. \\
\hline Grupo 7: Inglés & Tema 7: Teorías y tendencias de la traducción e interpretación. Evolución hasta las uiltimas décadas \\
\hline Grupo 8: Polaco & Tema 8: Formación y preparación de los traductores e intérpretes en España y en otro/s país/es. \\
\hline Grupo 10: Inglés & $\begin{array}{l}\text { Tema 10: Traductor jurado- Traductor jurídico- Traductor en los SSPP. Diferencias y estado de la cuestión en } \\
\text { diferentes países. }\end{array}$ \\
\hline Grupo 11: Francés & Tema 11: Glosario monolingüe de términos jurídicos (en español) \\
\hline Grupo 12: Francés & Tema 12: Glosario monolingüe de términos administrativos (en español) \\
\hline Grupo 15: Inglés & Tema 15: Glosario monolingïe de términos sanitarios (en español) \\
\hline Grupo 16: Inglés & $\begin{array}{l}\text { Tema 16: El sistema sanitario español: descripción y comparación con los sistemas sanitarios del Reino Unido y } \\
\text { de Estados Unidos. }\end{array}$ \\
\hline
\end{tabular}

Tabla 10. Temas trabajados en la actividad de redacción colaborativa 2008-2009

En general, se observa el interés por la elaboración de glosarios monolingües y los temas más prácticos. En el caso del segundo curso, que es más representativo porque participaron todos los alumnos y se trabajaron más temas, observamos que los grupos de francés y uno de los grupos de inglés eligieron temas más terminológicos (glosarios), el resto de los grupos de inglés y polaco temas más comparativos (comparación entre sistemas sanitarios, figuras de traductores y formación de los traductores en diferentes países) o incluso evolución de las teorías y tendencias de T\&I. Finalmente, los grupos de árabe y rumano se centraron en la definición y aclaración de conceptos fundamentales, de T\&I en general o en el ámbito sanitario. Como ya mencionábamos en el apartado 3.2, en el curso académico siguiente se añadieron otros temas más

Wikis como herramientas de trabajo colaborativo complementario y desarrollo de recursos para la formación en traducción a nivel universitario: análisis retrospectivo Bianca Vitalaru. Página 23 de 47 
específicos para orientar a los alumnos hacia el contenido específico que necesitaban para complementar la formación en otras asignaturas del máster. Tal y como anticipábamos, la mayoría de estos temas se cubrieron.

En general, hemos observado que los apartados redactados por los grupos incluían información adecuada y bien estructurada y reflejaban el interés por el tema, la organización del grupo y el alto nivel de implicación. Para incluir un ejemplo, en la Figura 11 podemos observar una muestra de redacción en la que 4 alumnos del grupo realizaron 25 ediciones de la página del apartado "Competencias del traductor y del intérprete":

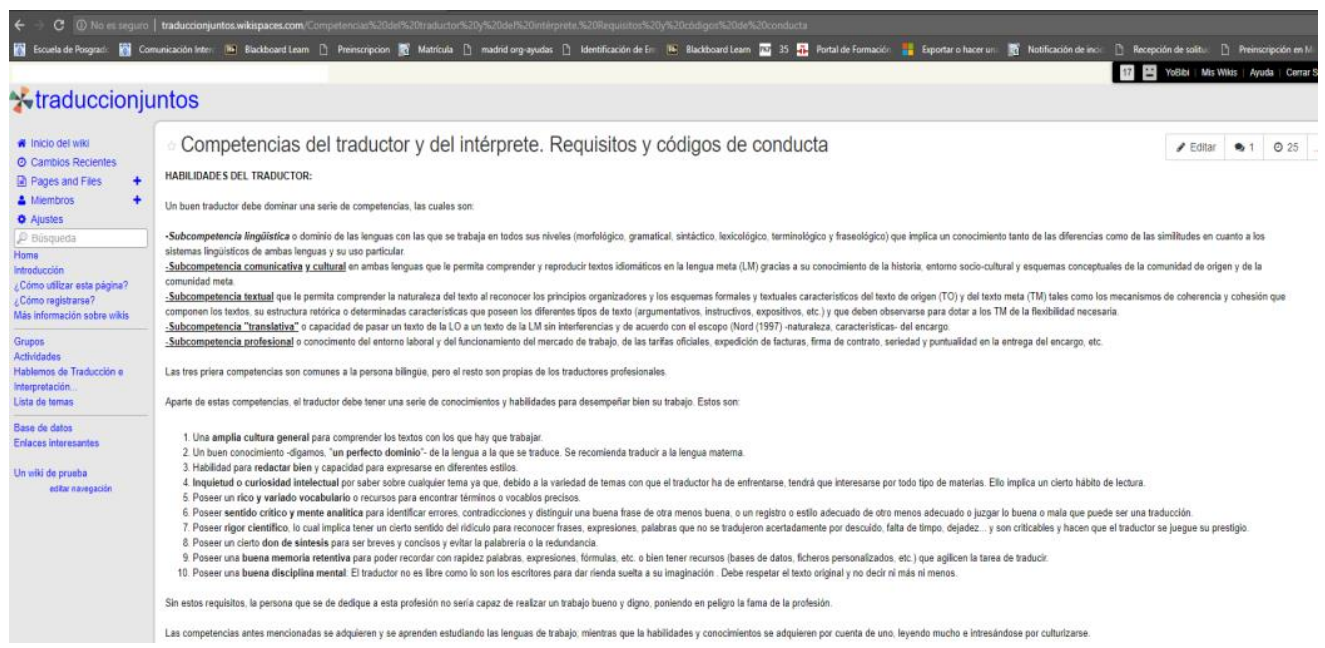

Figura 11. Redacción de contenido 2007-2008

En la siguiente figura se incluye una muestra de la creatividad mostrada por los alumnos de francés, que organizaron el glosario monolingüe, uno de los temas de la actividad de redacción conjunta de 2007-2008, por orden alfabético creando hipervínculos para cada letra:

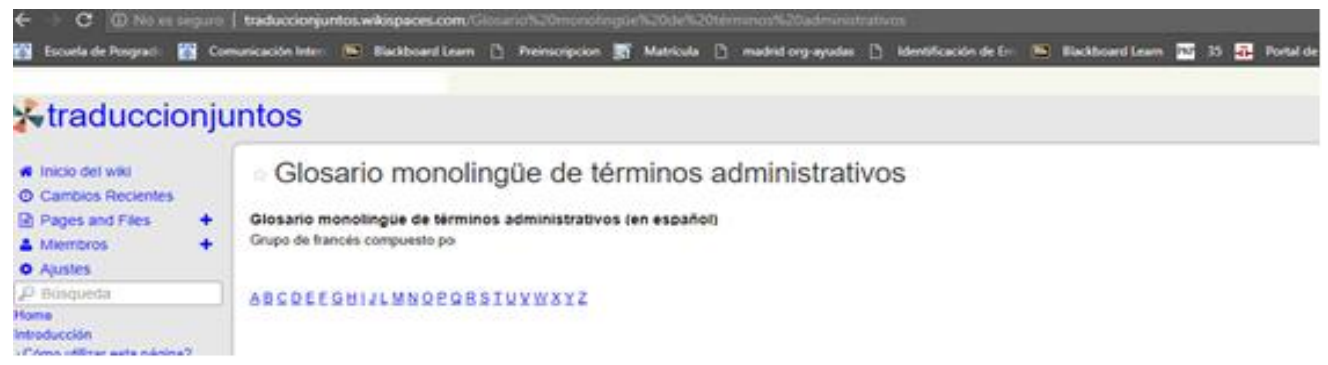

Figura 12. Glosario monolingüe como tema de la actividad de redacción conjunta

Además, aunque no se refleje en la figura, los alumnos incluyeron sus nombres en la portada para reflejar su autoría y su orgullo por un trabajo bien realizado.

Por otro lado, los resultados de la actividad de comparación de sistemas sanitarios de diferentes países, de 2010-2011, consisten, básicamente, en un compendio 
con contenido descriptivo y comparativo entre los sistemas de salud de los países propuestos:
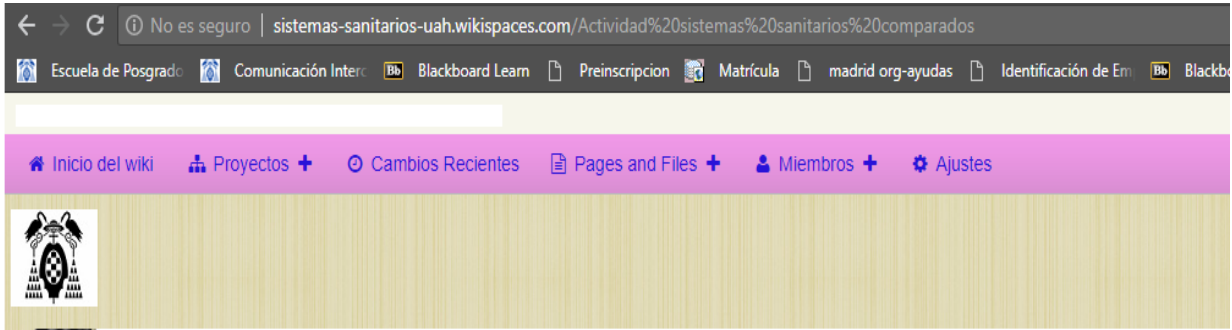

\section{Actividad sistemas sanitarios comparados}

SISTEMAS SANITARIOS

1. Sistema de salud en España

2. Sistema de salud en paises árabes

3. Sistema de salud en China

4. Sistema de salud en Japón

5. Sistema de salud en Francia

6. Sistema de salud en otros países de habla francesa

7. Sistema de salud en EEUU

8. Sistema de salud en Gran Bretaña

9. Sistema de salud en Irlanda

10. Sistema de salud en otros paises de habla inglesa

11. Sistema de salud en Polonia

12. Sistema de salud en Rumania

13. Sistema de salud en Rusia

14. Concepto de salud en paises orientales

Figura 13. Resultado actividad sistemas sanitarios comparados

Como se puede observar en la siguiente figura, con dos ejemplos de países (China y EE.UU.), para cada país se incluyeron los elementos específicos que los alumnos debían tener en cuenta en la realización de la actividad como la descripción general del sistema, el sistema de financiación, el tipo de acceso, los servicios y el sistema de urgencias, entre otros:

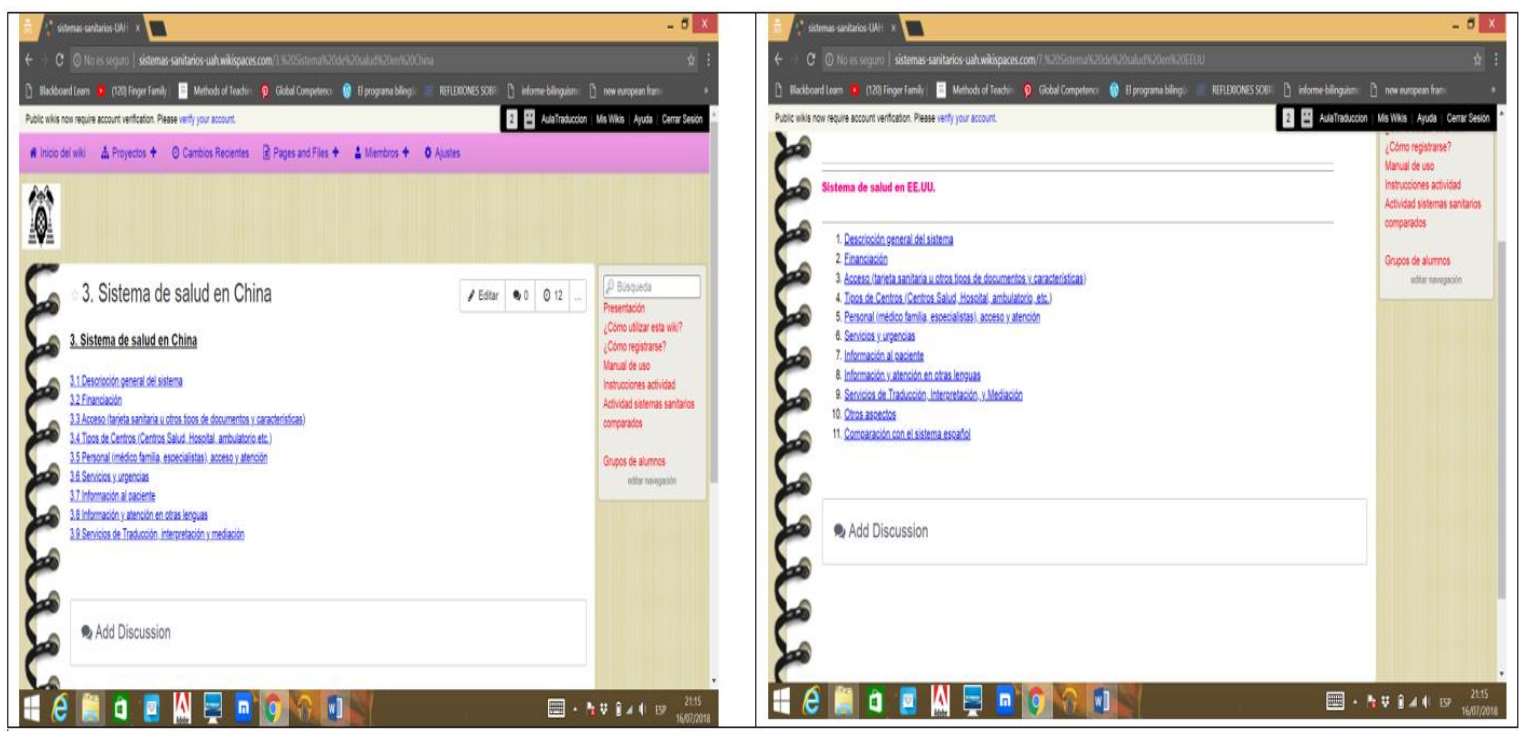

Figura 14. Ejemplos de elementos incluidos en la actividad; sistemas sanitarios de

China y EE.UU.

Wikis como herramientas de trabajo colaborativo complementario y desarrollo de recursos para la formación en traducción a nivel universitario: análisis retrospectivo Bianca Vitalaru. 
En el caso de los apartados que hacían referencia a otros países del habla en cuestión, los alumnos incluyeron Marruecos, Arabia Saudí y Argelia en el caso de los países árabes, Argelia, Malí, Marruecos, Mauritania y Senegal, en el caso de los países de habla francesa y Jamaica, Sudáfrica, Australia, Pakistán y Nueva Zelanda, en el caso de los demás países de habla inglesa, además de EE.UU., Gran Bretaña e Irlanda, ya incluidos en otros apartados. La repetición de Marruecos y Argelia en el caso de las primeras dos lenguas -árabe y francés- no ha repercutido en la realización de la actividad o en sus resultados ya que, a pesar de tener temas comunes, las perspectivas del alumnado de los dos grupos eran diferentes.

Como aspecto interesante subrayamos la propuesta del último tema "Concepto de salud en países orientales", que se incluyó para ver si los alumnos de chino estaban dispuestos a elegirlo sin instrucciones específicas sobre el tipo de contenido y su organización. Este tema en concreto fue elegido por uno de los grupos, que ha demostrado su creatividad y motivación, al tratarse de un tema de actualidad bastante problemático por la percepción distinta sobre el tema en las culturas europea y asiática.

\subsubsection{Participación y edición}

Los resultados estadísticos mencionados en Vitalaru (2009) se referían a la cuantificación de la participación de los alumnos y de los diferentes grupos en la actividad propuesta como actividad extra, que, en cierto modo, podía traducirse en el éxito o el fracaso de la actividad. En el curso 2007-2008, de los cinco pares de lenguas en las que se impartía el programa (español-inglés/francés/rumano/polaco/árabe), de un total de 54 alumnos, participaron 30 alumnos de los primeros cuatro grupos, es decir, un $55,55 \%$. En el caso del inglés y del francés participaron dos grupos para la actividad "Hablemos sobre T\&I" (es decir 50\% y 60\% de la totalidad de alumnos de cada grupo), un grupo de rumano y uno de polaco. Esto significaba un nivel de participación del 50\% en el caso de los alumnos de rumano y del $80 \%$ en el caso de los de polaco, considerando también que el número total de alumnos para estas dos combinaciones de lenguas era considerablemente menor, de $10 \mathrm{y}$, respectivamente, 6 alumnos.

Por otro lado, en los cursos académicos siguientes, al tratarse de una actividad obligatoria para todos los alumnos, el número de participantes fue mayor y la tasa de participación fue de $100 \%$ en ambos casos. El número de matriculados en el curso 2008-2009 fue de 51 alumnos (4 alumnos en árabe y polaco, 8 de rumano, 12 de francés y 23 de inglés) mientras que en el curso 2010-2011 de 96 ( 5 de polaco, 6 de ruso, 8 de francés, 9 de árabe, 11 de rumano, 28 de chino y 29 de inglés).

En la evaluación de estas actividades hemos dejado de contabilizar el nivel de participación y nos centramos en mejorar el diseño y las instrucciones de las tareas, el método de trabajo que tenían que emplear los alumnos y la terminología más significativa y de utilidad para los alumnos.

Para la evaluación de la herramienta y de la coordinación del alumnado era importante observar también el uso de la herramienta para completar, corregir o mejorar la información proporcionada. En este sentido, el historial de la herramienta permitía ver los cambios realizados y el número de ediciones totales de cada página. En nuestro caso, sin premiar o penalizar por el número de entradas de cada participante o grupo, observamos el uso más frecuente que se hacía en algunas de las especialidades o grupos de trabajo frente a otras, principalmente para explicar (en verde) y corregir, eliminar o

Wikis como herramientas de trabajo colaborativo complementario y desarrollo de recursos para la formación en traducción a nivel universitario: análisis retrospectivo Bianca Vitalaru. Página 26 de 47 
reestructurar (en rojo) información aportada por el compañero o por el mismo alumno en una edición anterior de la página (Figura 15):

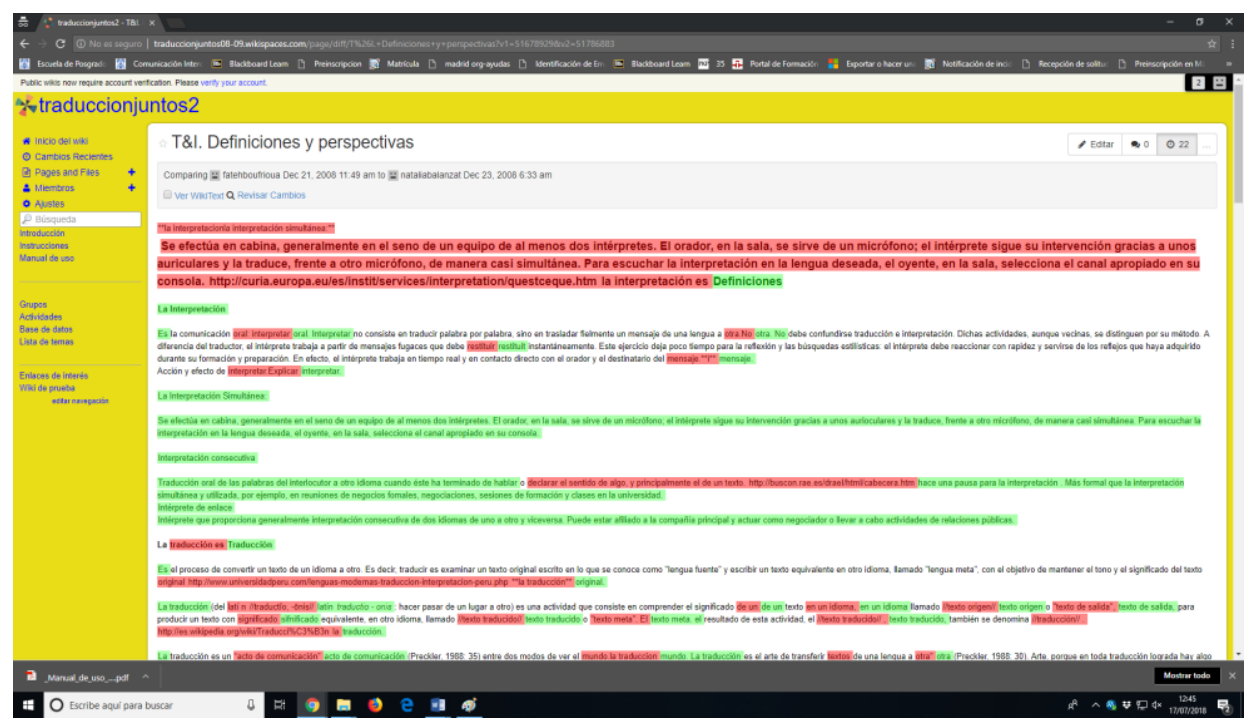

Figura 15. Historial y número de ediciones

Aunque en nuestro caso se ha evaluado el producto final como reflejo de la comunicación y de la adquisición de habilidades y no para contabilizar el nivel de participación, el número de ediciones y el hecho de que el alumnado haya utilizado esta función sin miedo a que afectara su calificación ha sido ilustrativa para la comunicación de los grupos y la versatilidad de la herramienta en sí. Además, fue representativo para la toma de decisiones con respecto a la idoneidad de un tema u otro en los diferentes cursos académicos. En la figura anterior se pueden observar los cambios realizados (aspectos añadidos y eliminados) hasta ese momento y el número de ediciones totales de esa página (22).

Otro ejemplo representativo del nivel de edición de las páginas en actividades de redacción colaborativa es el de la actividad de comparación de sistemas sanitarios de 2010-2011. En la Figura 16 se pueden observar algunas ediciones y el número total de ediciones de la página (24):

Wikis como herramientas de trabajo colaborativo complementario y desarrollo de recursos para la formación en traducción a nivel universitario: análisis retrospectivo Bianca Vitalaru. 


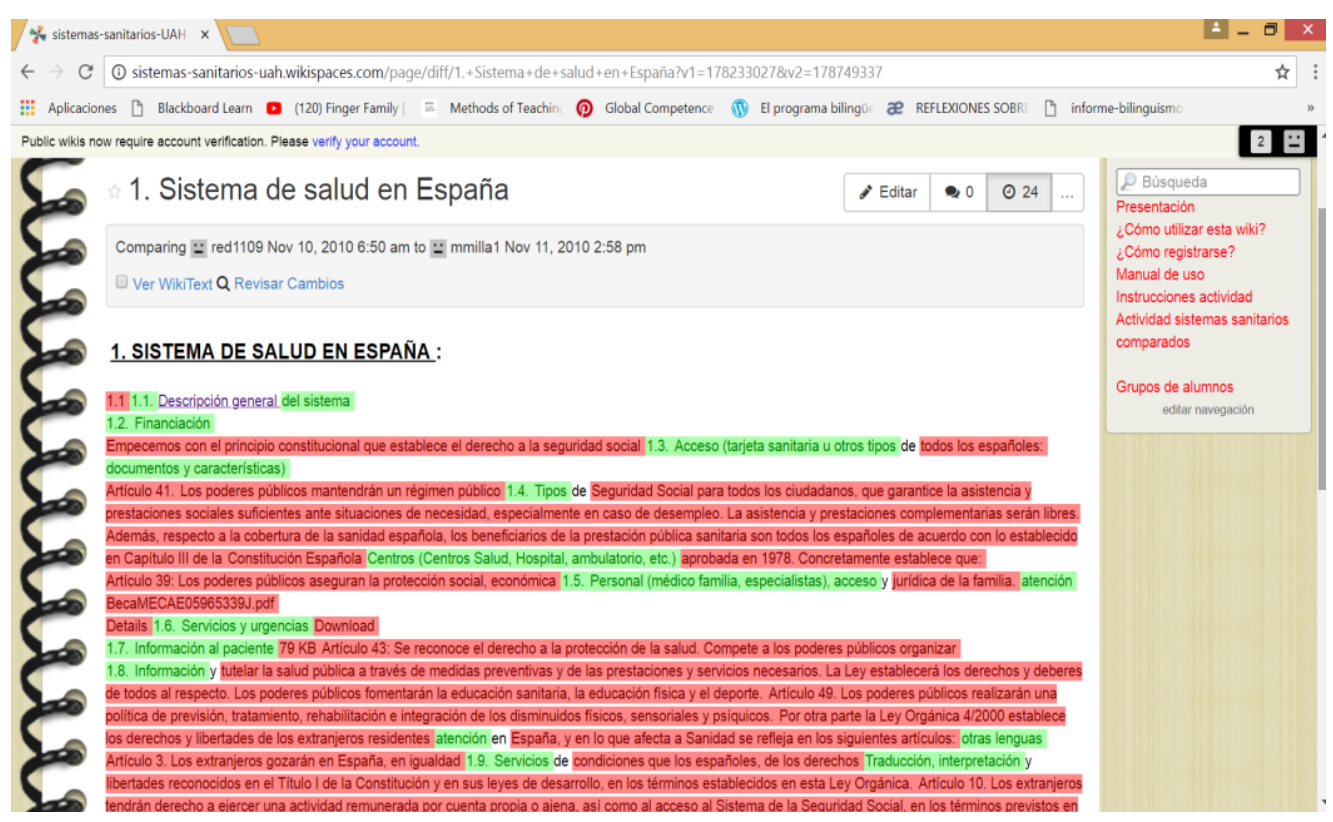

Figura 16. Historial de ediciones sistema de salud en España

En el caso de esta actividad hemos contabilizado el número de ediciones del apartado de cada país para determinar cuáles de los grupos habían utilizado más la herramienta, sin que afectara su calificación. El número de ediciones más alto es el de Rusia, con 49 ediciones y, en general, el número varía entre 12 y 49 para los apartados con más ediciones y entre 4 y 10 para los apartados con menos ediciones:

\begin{tabular}{|l|l|}
\hline Número más alto de ediciones & Número más bajo de ediciones \\
\hline RUSIA: 49 & CONCEPTO DE SALUD: 10 \\
EEUU: 40 & IRLANDA: 8 \\
ESPAÑA: 24 & GRAN BRETAÑA: 7 \\
OTROS PAÍSES DE HABLA & PAÍSES ÁRABES: 7 \\
INGLESA: 22 & RUMANÍA: 5 \\
POLONIA: 24 & OTROS PAÍSES DE HABLA \\
FRANCIA: 15 & FRANCESA: 4 \\
CHINA: 12 & \\
JAPÓN: 12 & \\
& \\
\hline
\end{tabular}

Tabla 11. Comparación número de ediciones actividad sistemas sanitarios comparados

A falta de datos en cuanto al número de ediciones por alumno y a una investigación cualitativa más profunda, para poder analizar el origen de los alumnos que participaron en cada tema, hemos elaborado una tabla con el número de alumnos de origen español y otra de la especialidad para cada uno de los temas tratados:

Wikis como herramientas de trabajo colaborativo complementario y desarrollo de recursos para la formación en traducción a nivel universitario: análisis retrospectivo Bianca Vitalaru. Página 28 de 47 


\begin{tabular}{|l|l|l|l|l|l|}
\hline $\begin{array}{l}\text { País con n } \\
\text { más alto de } \\
\text { ediciones }\end{array}$ & $\begin{array}{l}\text { Origen } \\
\text { alumnos } \\
\text { (España) }\end{array}$ & $\begin{array}{l}\text { Origen } \\
\text { alumnos } \\
\text { (país de la } \\
\text { especialidad) }\end{array}$ & $\begin{array}{l}\text { País con no } \\
\text { más bajo de } \\
\text { ediciones }\end{array}$ & $\begin{array}{l}\text { Origen } \\
\text { alumnos } \\
\text { (España) }\end{array}$ & $\begin{array}{l}\text { Origen } \\
\text { alumnos } \\
\text { (país de la } \\
\text { especialidad) }\end{array}$ \\
\hline Rusia & & 6 & C. salud & & 9 \\
\hline EE.UU. & 2 & 4 & Irlanda & 3 & 2 \\
\hline España & 6 & & Gran Bretaña & 6 & \\
\hline $\begin{array}{l}\text { Habla } \\
\text { inglesa }\end{array}$ & 4 & 1 & Países árabes & & 9 \\
\hline Polonia & & 5 & Rumanía & & 11 \\
\hline Francia & 3 & & $\begin{array}{l}\text { Habla } \\
\text { francesa }\end{array}$ & 3 & 2 \\
\hline China & & 10 & & & \\
\hline Japón & & 9 & & & \\
\hline
\end{tabular}

Tabla 12. Comparación origen alumnos actividad sistemas sanitarios comparados

Como podemos observar en las Tablas 11 y 12, en el caso de esta actividad parece ser que los alumnos más activos desde el punto de vista virtual fueron gran parte de los alumnos de origen español, ruso, de habla inglesa, polaco, francés y chino. Los alumnos con menos ediciones fueron los alumnos de origen árabe y rumano. La posible explicación para esta tendencia puede ser el contacto menos frecuente con este tipo de tecnología en la formación previa del alumnado en el caso del alumnado árabe y la delegación de la responsabilidad más técnica hacia el representante en el caso del alumnado rumano. Desde este punto de vista, la explicación es bastante limitada ya que no contamos con más datos al respecto.

\subsection{Resultados de las actividades terminológicas}

Igual que en el caso anterior, analizaremos los resultados obtenidos desde dos puntos de vista: material y nivel de participación, subrayando aspectos considerados de importancia en cuanto a la utilización de las wikis para el objetivo propuesto, es decir la elaboración de recursos lexicográficos partiendo del trabajo colaborativo (Vitalaru, 2009).

\subsubsection{Resultados materiales}

En Vitalaru (2009) describíamos los resultados materiales de las dos actividades terminológicas del curso 2007-2008 (en las que colaboraron 20 y, respectivamente, 44 alumnos) refiriéndonos a los diferentes glosarios especializados bilingües obtenidos (partiendo del español) y que eran específicos para diferentes temas del ámbito sanitario: pediatría (francés), enfermedades comunes (inglés), SIDA-VIH (francés y rumano) y fobias (rumano); así como del ámbito jurídico-administrativo: conceptos jurídicos fundamentales (inglés), terminología derecho civil (inglés) y penal (francés), terminología extranjería (árabe y rumano) y terminología derecho laboral (árabe y francés).

Wikis como herramientas de trabajo colaborativo complementario y desarrollo de recursos para la formación en traducción a nivel universitario: análisis retrospectivo Bianca Vitalaru. Página 29 de 47 
En el curso académico 2008-09 (que reunía a un total de 54 alumnos) también se elaboraron glosarios bilingües de manera conjunta dentro del ámbito jurídicoadministrativo, concretamente glosarios de derecho penal y laboral, cuyas fases de trabajo fueron parecidas a las de los glosarios anteriores. Se elaboraron glosarios de derecho penal en las cinco combinaciones lingüísticas del máster (español-árabe, francés, inglés, polaco y rumano) y de derecho penal en las últimas cuatro, tal y como se puede ver en las Figuras 17 y 18:

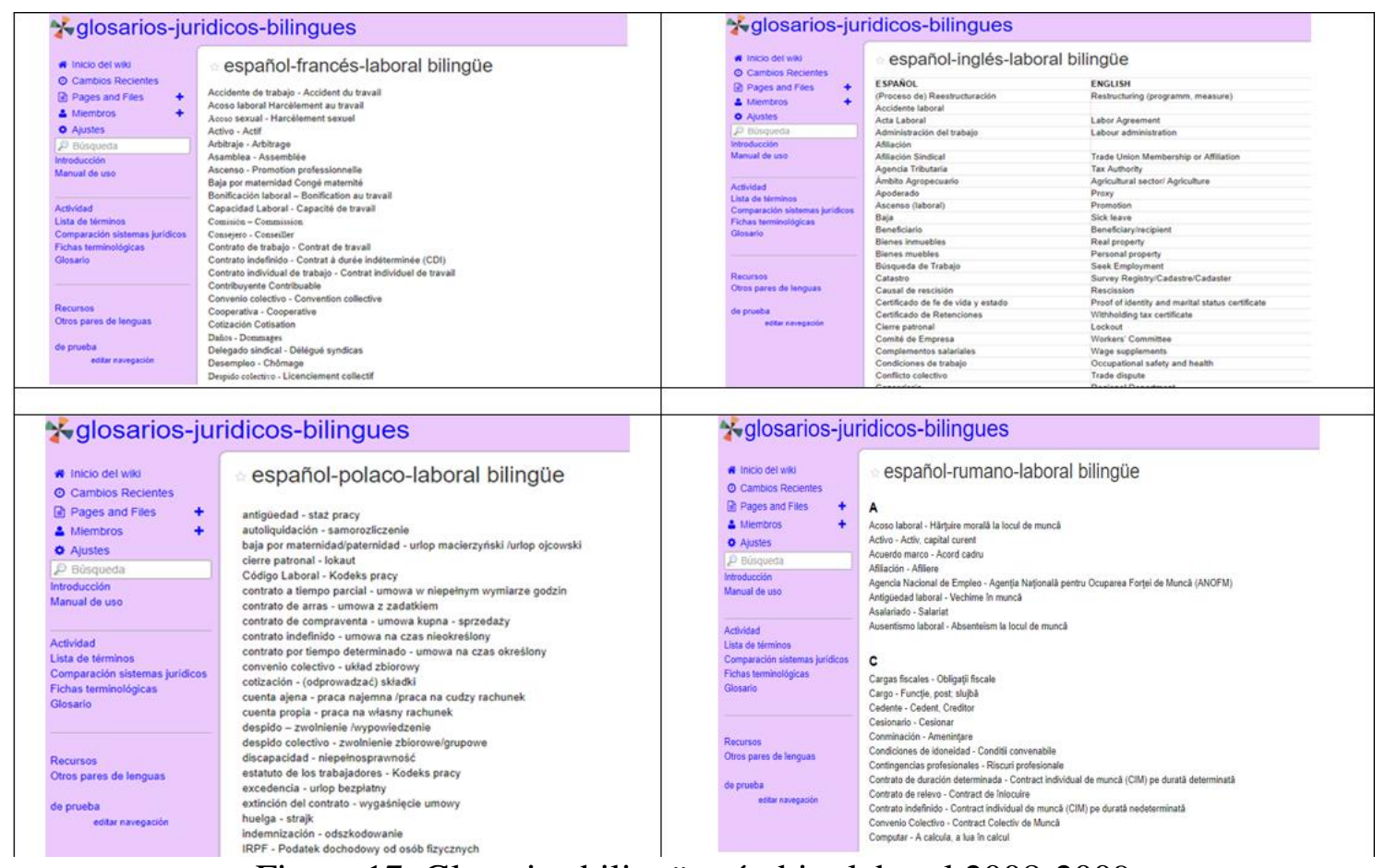

Figura 17. Glosarios bilingües ámbito laboral 2008-2009

Wikis como herramientas de trabajo colaborativo complementario y desarrollo de recursos para la formación en traducción a nivel universitario: análisis retrospectivo Bianca Vitalaru. 


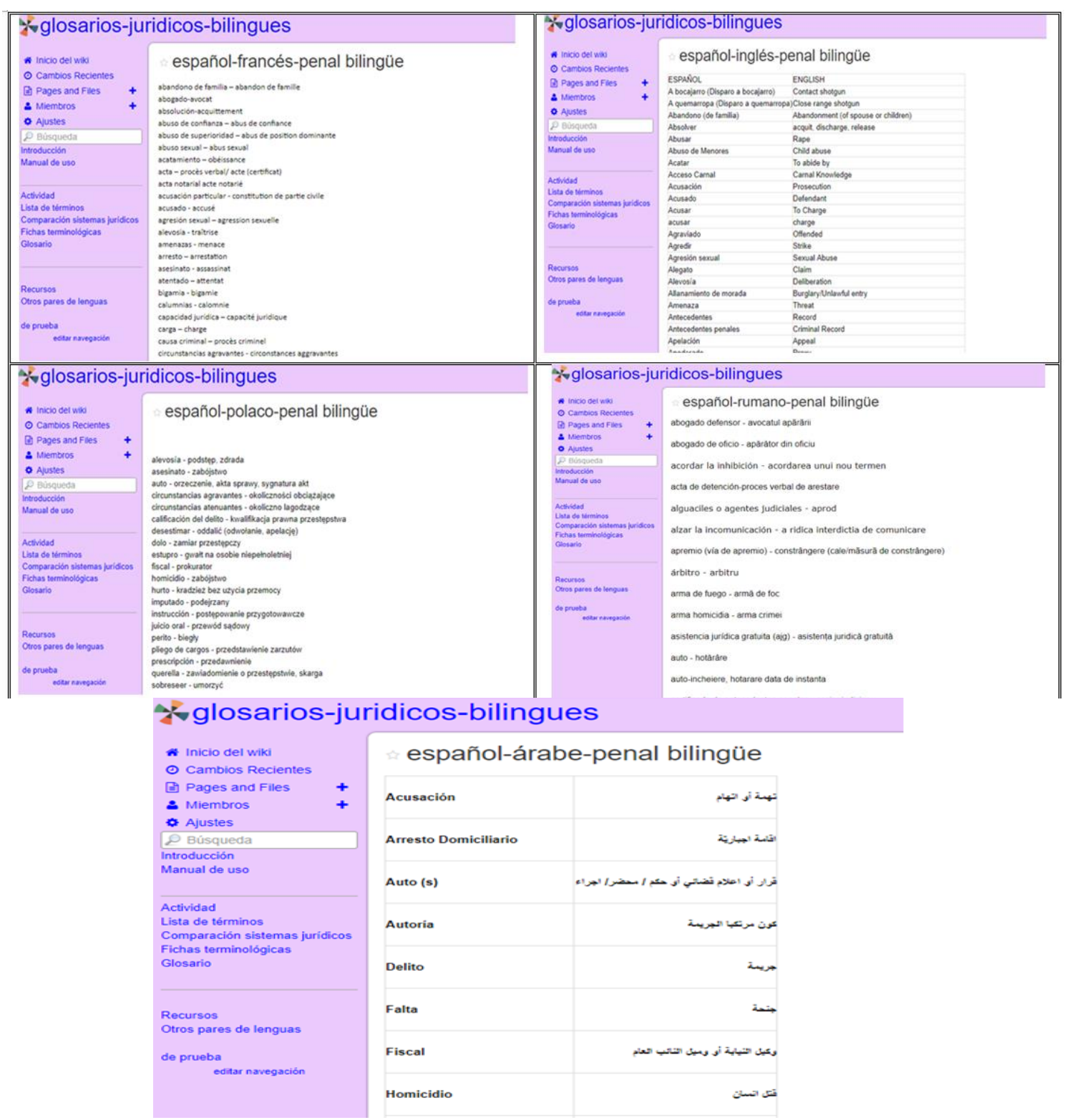

Figura 18. Glosarios bilingües ámbito penal 2008-2009

El número de términos requeridos por alumno era de 20 términos, por lo que el número de términos de cada uno varía en función del número de alumnos de cada grupo, entre 40 (penal árabe y laboral polaco) y máximo 260 (penal) y 140 (laboral) para el grupo de inglés.

En los cursos académicos 2008-2009 y, respectivamente, 2009-2010 se elaboraron dos glosarios multilingües del ámbito sanitario en diferentes lenguas:

1) Un glosario sanitario multilingüe general en español-árabe-francés-ingléspolaco-rumano (Figura 19): 


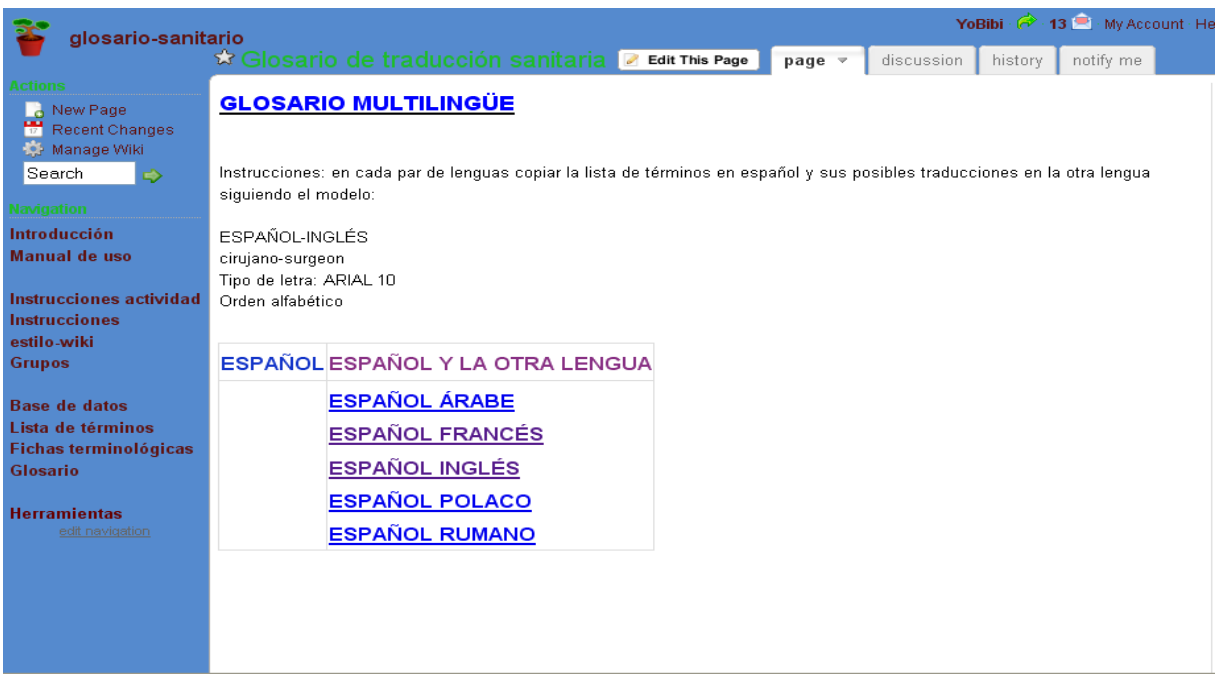

Figura 19. Glosario sanitario multilingüe 2008-2009

En la siguiente figura se encuentra una imagen del glosario generado en cada lengua:

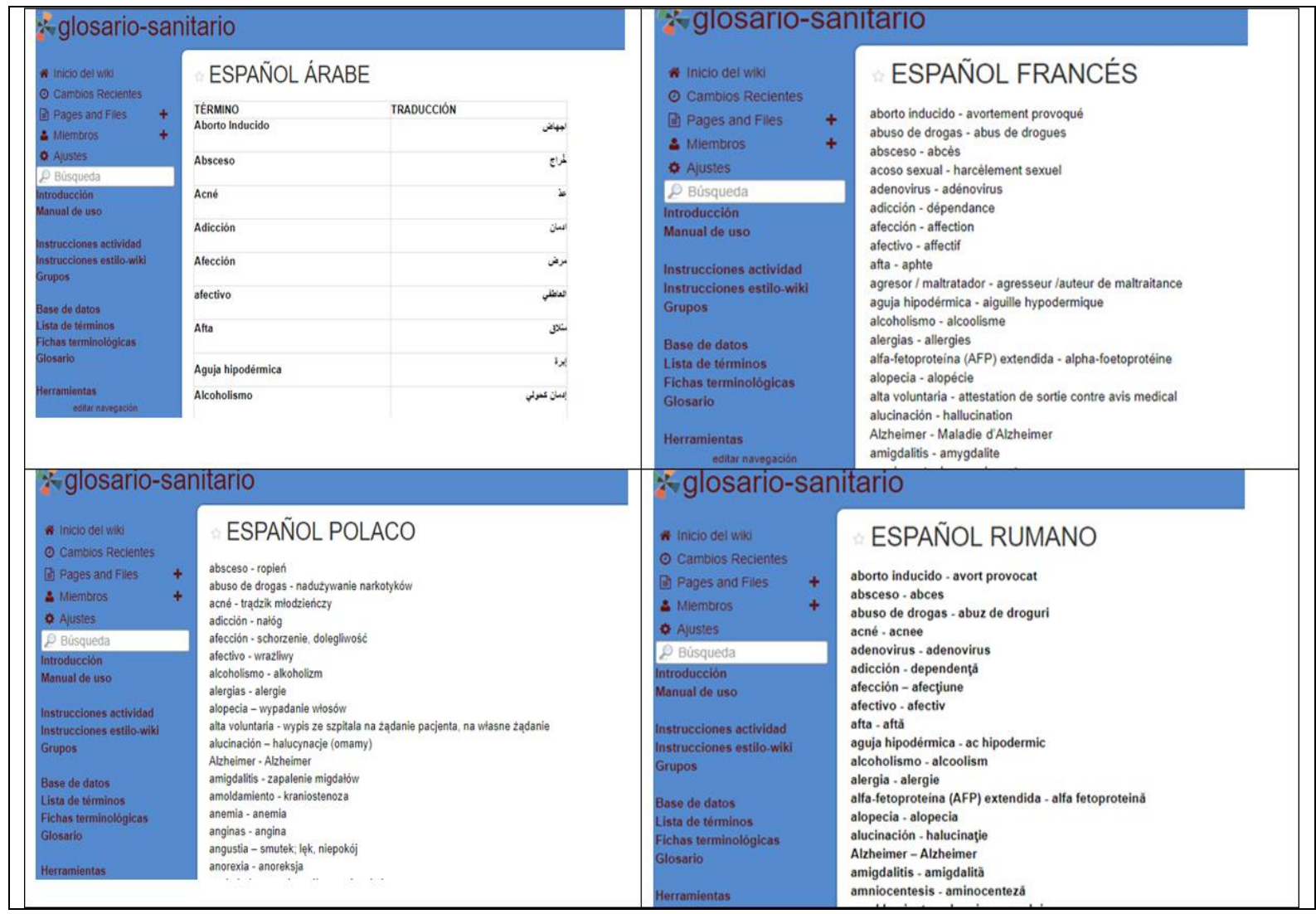

Wikis como herramientas de trabajo colaborativo complementario y desarrollo de recursos para la formación en traducción a nivel universitario: análisis retrospectivo Bianca Vitalaru. 


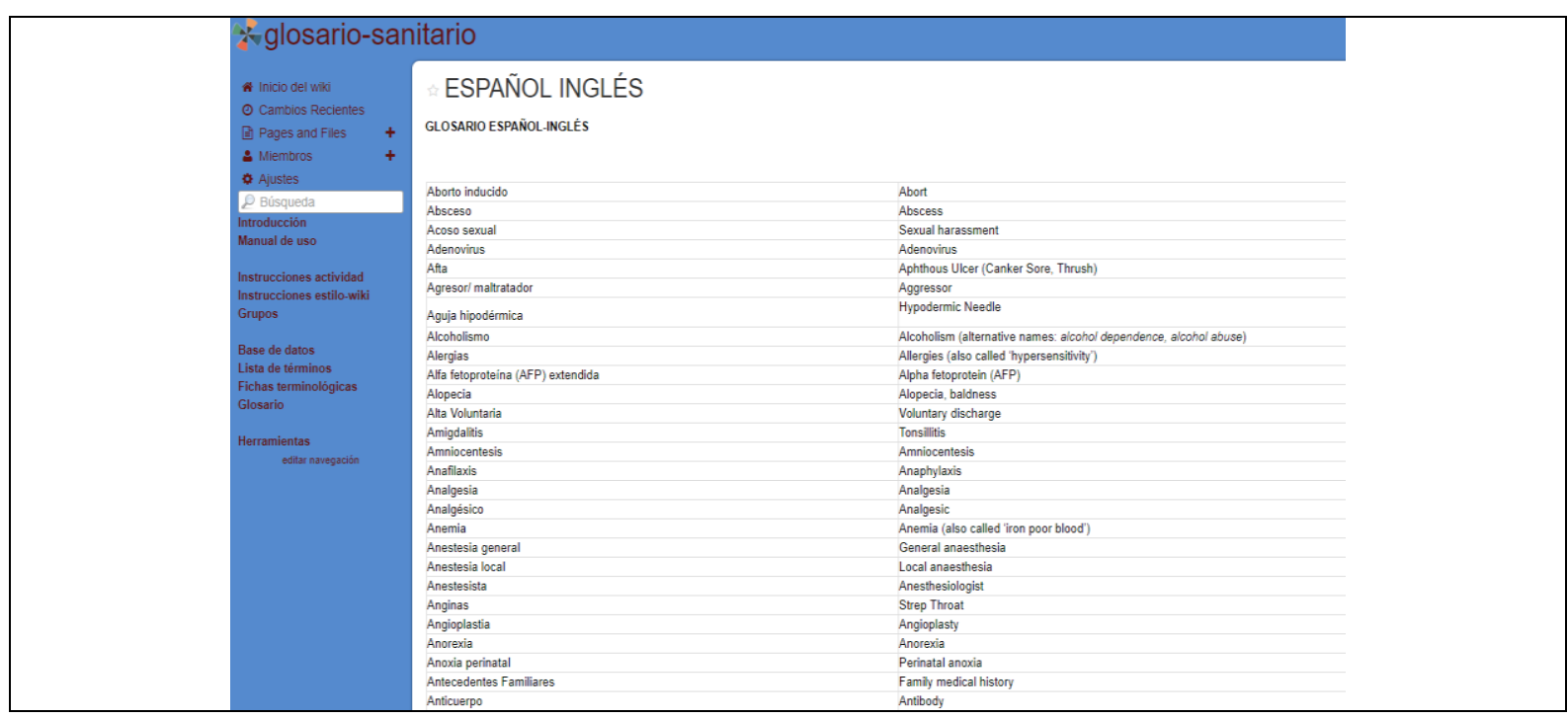

Figura 20. Glosario sanitario multilingüe 2008-2009

2) Un glosario multilingüe de enfermedades más comunes en español-árabe-chinoinglés-rumano-ruso (Figura 21):

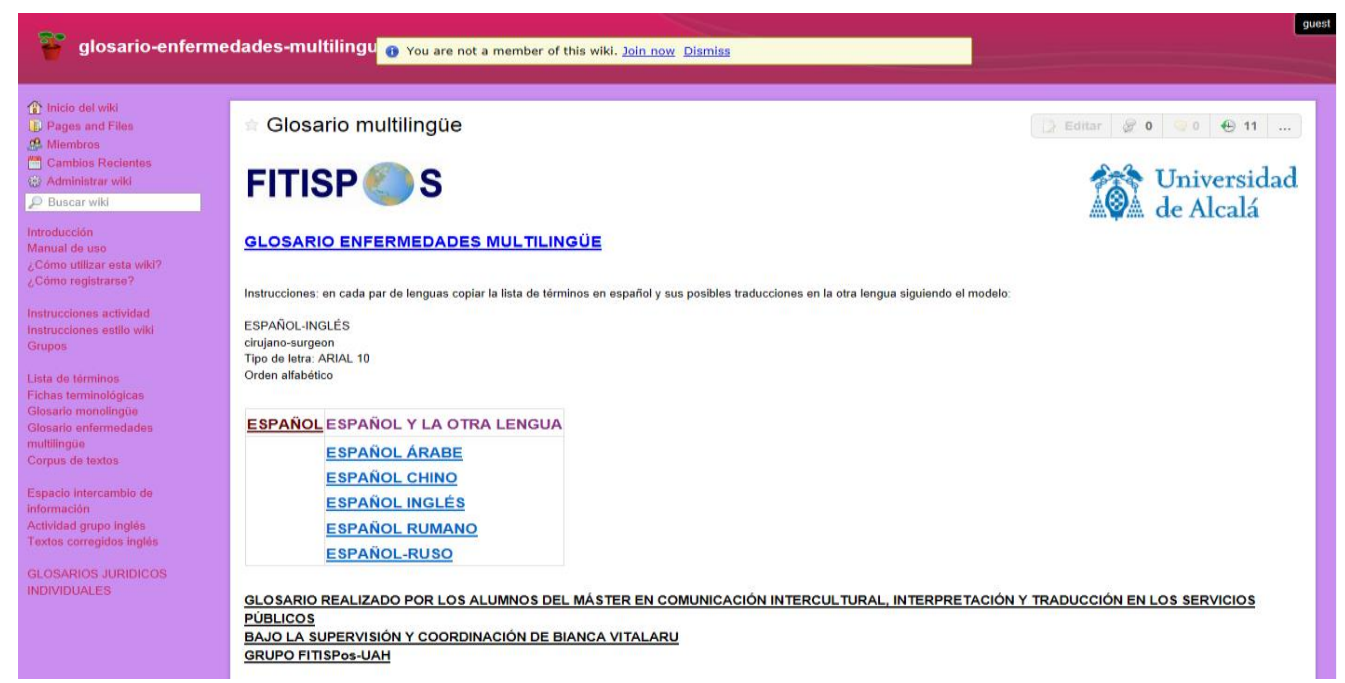

Figura 21. Glosario enfermedades multilingüe 2009-2010

En el caso del glosario enfermedades multilingüe de 2009-2010, teniendo en cuenta el número de alumnos de cada especialidad lingüística y el reparto equitativo de términos entre los diferentes grupos formados, se tradujeron los términos de los 10 tipos de enfermedades indicadas en la Tabla 8, del apartado 5.2. Teniendo en cuenta el total de 510 términos seleccionados por el profesor, todos los términos se tradujeron completamente al inglés y al chino y parcialmente (aproximadamente la mitad) al resto de las lenguas. Se incluye un ejemplo en la Figura 22: 


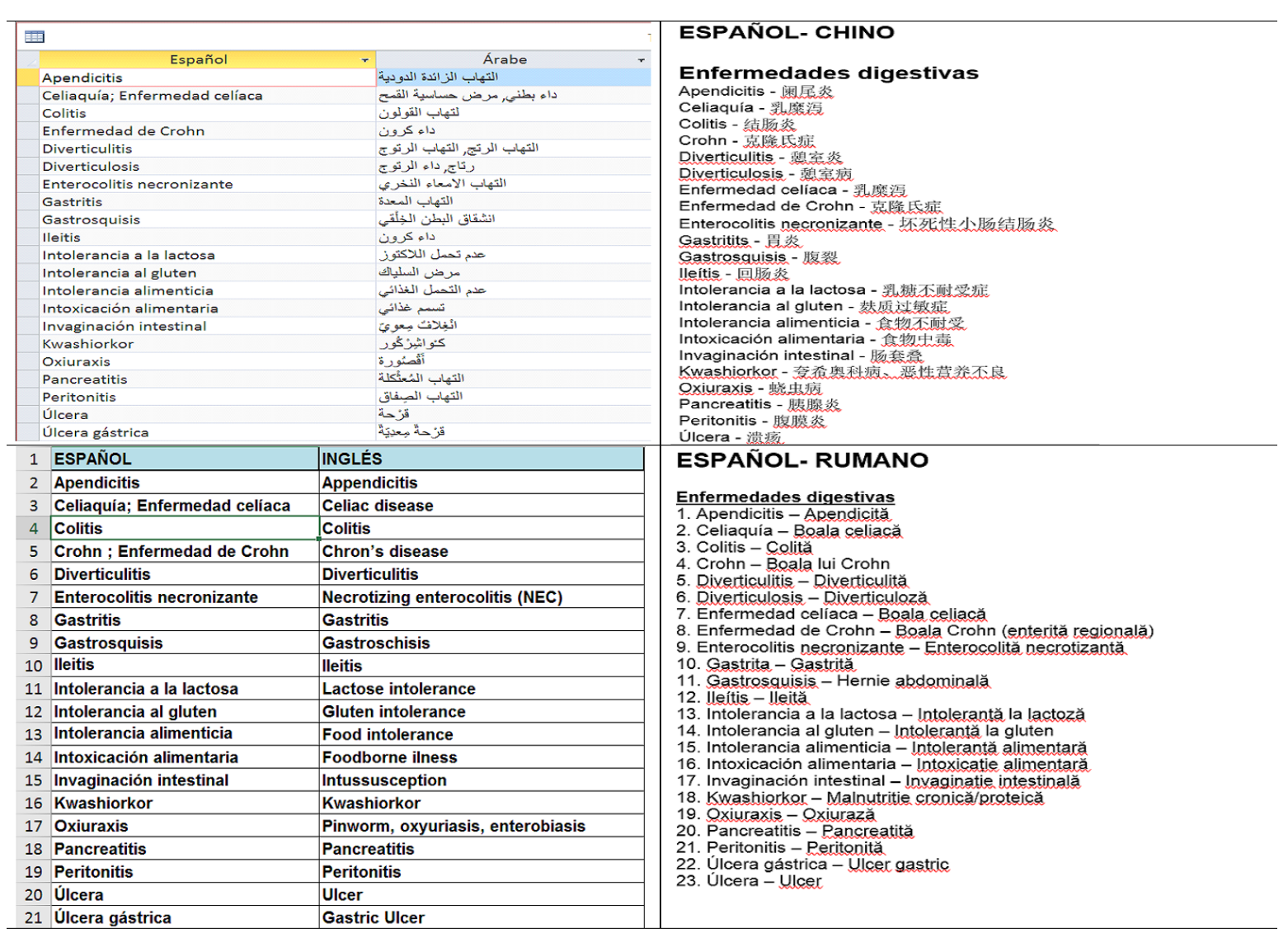

Figura 22. Ejemplo enfermedades digestivas en varias lenguas 2009-2010

Cabe señalar que el resultado final de estas actividades no consistió solamente en los glosarios finales organizados alfabéticamente para facilitar su búsqueda sino también en una ficha terminológica más detallada y organizada temáticamente en cada una de las lenguas. Por ejemplo, la que sigue extraída de la ficha de "Instrumentos médicos" del curso 2008-2009:

\begin{tabular}{|c|c|c|c|c|c|c|c|c|}
\hline B & Audiómetro & $\begin{array}{l}\text { El audiómetro es un } \\
\text { instrumento de } \\
\text { tecnologia digital y } \\
\text { diseño ultra } \\
\text { compacto que } \\
\text { permite realizar } \\
\text { audiometrías } \\
\text { tonales por vía } \\
\text { aérea, por vía ósea } \\
\text { y logoaudiometrías } \\
\text { con micrófono o } \\
\text { grabador. }\end{array}$ & $\begin{array}{l}\text { Aunque ya existen } \\
\text { audiómetros en el } \\
\text { mercado (diseñados } \\
\text { para medir el grado } \\
\text { de audición de un } \\
\text { paciente), la empresa } \\
\text { Lolimsa creó uno } \\
\text { más versátil que } \\
\text { permite exámenes } \\
\text { audiométricos a } \\
\text { pedido (logra medir } \\
\text { infinidad de } \\
\text { frecuencias). }\end{array}$ & 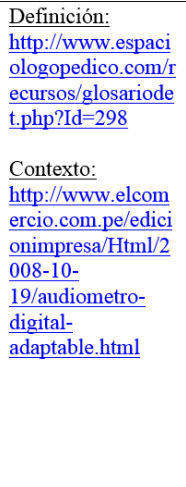 & Audiometer & $\begin{array}{l}\text { An electrical } \\
\text { instrument } \\
\text { for } \\
\text { measuring } \\
\text { the } \\
\text { threshold of } \\
\text { hearing for } \\
\text { pure tones } \\
\text { of normally } \\
\text { audible } \\
\text { frequencies } \\
\text { generally } \\
\text { varying } \\
\text { from } 200 \text { to } \\
8000 \text { hertz } \\
\text { and } \\
\text { recorded in } \\
\text { decibels. }\end{array}$ & $\begin{array}{l}\text { AUSSCO } \\
\text { INC has } \\
\text { been } \\
\text { supplying } \\
\text { medical } \\
\text { products } \\
\text { and } \\
\text { instruments } \\
\text { for } 40+ \\
\text { years. We } \\
\text { specialize in } \\
\text { providing } \\
\text { industries, } \\
\text { schools, } \\
\text { physicians } \\
\text { and clinics } \\
\text { with the } \\
\text { equipment, } \\
\text { software }\end{array}$ & 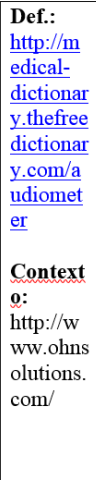 \\
\hline
\end{tabular}

Figura 23. Ficha terminológica Instrumentos médicos. 2008-2009

Por su aplicabilidad considerando los objetivos del trabajo, a continuación, explicaremos algunas de las dificultades observadas y de los aspectos importantes para tener en cuenta de cara al diseño de futuras actividades similares.

Wikis como herramientas de trabajo colaborativo complementario y desarrollo de recursos para la formación en traducción a nivel universitario: análisis retrospectivo Bianca Vitalaru. Página 34 de 47 
Algunas de las dificultades que los alumnos tuvieron y detectadas por los dos profesores responsables en la corrección de la tarea del ámbito jurídico de 2008-2009 fueron no tanto la traducción sino el trabajo terminológico, concretamente, la selección de términos más representativos de un ámbito, especialmente en el ámbito jurídico, y de fuentes utilizadas para extraer la definición o el contexto de la ficha terminológica. Por ejemplo, la inclusión de términos más generales ("vetar", verificación", "carga" en el glosario penal y "matriz" en el glosario laboral) o una parte incompleta de una unidad terminológica ("quebrantamiento" en el glosario penal y "otorgamiento" en el glosario laboral).

Otro aspecto menos convencional fue la inclusión de dos términos o unidades terminológicas en la misma entrada por el grupo de rumano para subrayar que se trataba de términos con diferentes significados cuya traducción suponía cierta dificultad: "libertad condicional vs libertad vigilada", "medidas de seguridad vs medidas cautelares" o "proceso sumario vs proceso ordinario (vs extraordinario)". Esto refleja, en cierto modo, su propia concienciación sobre la dificultad probablemente en base a los apuntes de las clases presenciales. También la categoría general y la tipología más común "lesiones (graves y leves)" o la inclusión de especificaciones contextuales "perito (judicial)". También fue frecuente esta estrategia en el glosario laboral de inglés: "(proceso de) reestructuración", "percibir (prestaciones)" o "ascenso (laboral)".

Otro aspecto que se observó fue la repetición de términos en el glosario generado por el grupo de inglés de 2008-2009 en el caso de términos como "recurrente", "mandato", "mala fe" o "sanción" con la misma traducción y "perseguir", "pena", "libertad condicional" con dos traducciones distintas. Esto sugiere, en primer lugar, cierta falta de coordinación entre los grupos e incluso la necesidad de una figura que revise posibles incidencias antes de la finalización de la tarea. En segundo lugar, implica la necesidad de prever este tipo de incidencias, así como de establecer un procedimiento específico para la inclusión de unidades terminológicas y términos polisémicos.

En el caso de los glosarios sanitarios observamos un proceso de mejora con respecto a las instrucciones y procedimiento seguido por los profesores responsables de la tarea durante varios cursos académicos. En el curso 2007-2008 algunas de las dificultades detectadas fueron la falta de organización o delimitación temática de los términos que el alumnado propuso dentro de las categorías creadas por los profesores y la inclusión de términos menos específicos de esa categoría (síntomas u tratamientos como parte de las enfermedades). Algunos ejemplos son: "crisis de ansiedad", "ansiedad anticipatoria", "evitación", "elusión" e incluso tipos de terapias ("terapia cognitivo-conductual (TCC)" y "terapia graduada de exposición") incluidos en el glosario sobre fobias de rumano. Cabe señalar que estos alumnos en concreto eran conscientes de esta irregularidad porque se incluyeron por separado dentro del documento como una categoría aparte, sin denominación específica. Sin embargo, aunque no de manera tan específica como en el caso de la actividad del ámbito jurídico, en varias lenguas se incluyeron síntomas o mezcla de conceptos. Teniendo este aspecto en mente, en los cursos siguientes se hicieron modificaciones para orientar al alumnado con respecto a lo que sería más eficaz desde el punto de vista del aprendizaje temático. En el curso 2008-2009 se proporcionaron como categorías también las siguientes: "Tratamientos e intervenciones (tipos)", "Síntomas y efectos", "Personal médico y organización del hospital", "Tipos de documentos y expresiones típicas" e "Instrumentos médicos" mientras que en 2009-2010 se proporcionaron los términos de

Wikis como herramientas de trabajo colaborativo complementario y desarrollo de recursos para la formación en traducción a nivel universitario: análisis retrospectivo Bianca Vitalaru.

Página 35 de 47 
cada tipo de enfermedad para que los alumnos se centraran en elaborar un glosario específico solo de enfermedades.

\subsubsection{Participación y edición}

Haciendo referencia al curso 2007-2008, en Vitalaru (2009) destacábamos, desde el punto de vista estadístico, la participación de alumnos de las diferentes especialidades lingüísticas del máster: $50 \%$ de los alumnos de inglés para el glosario sanitario y $100 \%$ para el jurídico, $75 \%$ de los de francés para los dos glosarios, $90 \%$ de los de rumano para el glosario sanitario y $15 \%$ para el jurídico, $0 \%$ de los de árabe para el glosario sanitario y $100 \%$ para el jurídico y $0 \%$ de los alumnos de polaco para los dos glosarios (aunque hay que remarcar que en la actividad de redacción colaborativa habían elaborado un glosario jurídico monolingüe). Además, concluimos, basándonos en el análisis del nivel de participación y edición de las páginas wiki en los meses de realización de las actividades (noviembre/diciembre; enero/febrero) que el interés para el trabajo había crecido de una actividad a otra. Señalábamos también que los alumnos que habían realizado algunas de las actividades habían comprendido la utilidad de la actividad propuesta en su proceso de aprendizaje y la importancia del trabajo en grupo y habían decidido seguir, motivando a otros grupos también. Finalmente, mencionábamos que su participación dependía también del interés o preferencia por un ámbito u otro y de sus propios conocimientos (algunos grupos participaron sólo en una actividad).

Desde este punto de vista consideramos útil reflexionar con respecto a la variación por lenguas y temas que reflejan el interés del alumnado mediante ejemplos de los materiales elaborados por el alumnado durante estos años, así como ver cómo los cambios de planteamiento han afectado el nivel de participación y los resultados obtenidos.

En el curso académico 2007-2008 participaron 44 (86\%) alumnos en la elaboración de glosarios del ámbito jurídico y 20 (39\%) en los glosarios del ámbito sanitario, de un total de 51. A partir del curso académico 2008-2009 las actividades se incluyeron como obligatorias, por lo que el número de alumnos que participaron ha subido significativamente a 54 alumnos en dicho curso académico y a 73 alumnos en el curso 2009-2010, cuando también se incorporaron las especialidades de ruso y chinoespañol. La distribución por lenguas fue bastante dispar, con 4 alumnos de árabe y polaco, 8 de rumano, 12 de francés y 23 de inglés en el curso 2008-2009 y 4 alumnos de árabe, 5 de rumano, 6 de ruso, 15 de francés, 16 de chino y 27 de inglés en el curso 2009-2010.

Por otro lado, aunque no se haya tenido en cuenta en la evaluación, el número de ediciones de las páginas, que reflejan los cambios realizados en dos colores (verde y rojo), también puede considerarse generalmente como un indicio de participación e implicación en la actividad:

Wikis como herramientas de trabajo colaborativo complementario y desarrollo de recursos para la formación en traducción a nivel universitario: análisis retrospectivo Bianca Vitalaru. Página 36 de 47 


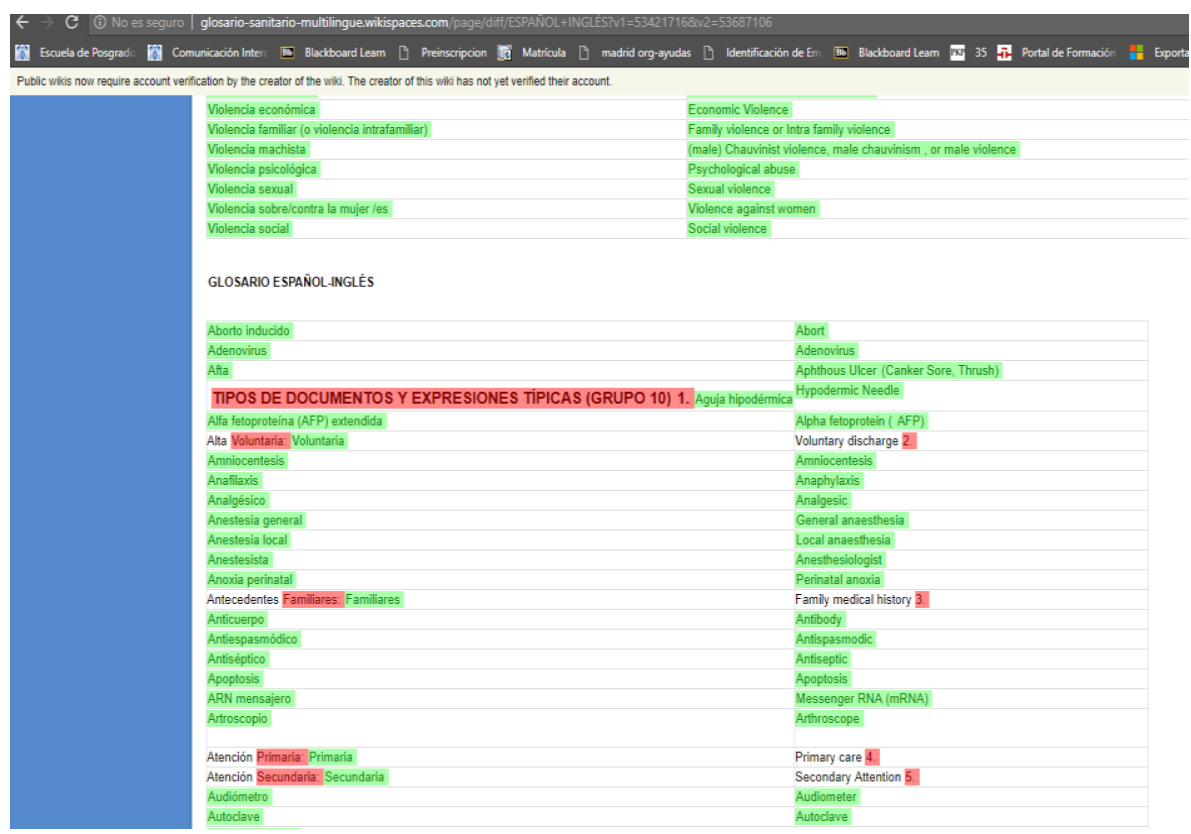

Figura 24. Edición del glosario multilingue 2008-2009; parte de inglés

Para poner un ejemplo, en la elaboración del glosario multilingüe del curso académico 2008-2009, el número de ediciones de la parte de glosario por lenguas ha sido el siguiente: árabe: 1, francés: 36, inglés: 14, polaco: 21 y rumano: 11. Observamos que los grupos de francés y polaco han tenido un número más alto de ediciones, lo que indica que no necesariamente han intervenido los grupos con un número más alto de alumnos, como el de inglés, con 23 alumnos, frente al de polaco, con 4 alumnos y de francés, con 12 alumnos.

Finalmente, igual que en el caso de la actividad de redacción de 2010-2011, también observamos que determinados grupos de lenguas (de árabe y de rumano en este caso, e igual que en el caso anterior) prefirieron colgar el producto final y el nivel de edición de la página wiki en sí era mucho menor. Al no contar con más datos desconocemos las causas. Suponemos que esto puede deberse a razones como, por ejemplo, la facilidad del delegado para recoger los términos trabajados por los compañeros, al ser el responsable de la revisión, para posteriormente realizar cambios en la plataforma en el caso de rumano y la formación previa menos orientada al uso de las nuevas tecnologías en trabajos colaborativos de algunos sistemas educativos de países árabes. Los grupos más activos desde este punto de vista han sido los de francés y polaco, que también tenían una puntuación más alta en el caso de la actividad anterior. Como tarea pendiente sería interesante profundizar más con respecto a la formación previa del alumnado y los motivos que les convierte en editores 'más' o 'menos' activos en este tipo de actividades.

\subsection{Desarrollo de habilidades específicas}

\subsubsection{Trabajo en grupo y comunicación en el foro de debate}

Bruns y Humphreys (2005 citado por Araujo Portugal, 2014: 9) indicaban que el espacio de los wikis implica la existencia de "un proceso dinámico de construcción" con una serie de acuerdos a los que se llega y resolución de conflictos necesarios para poder

Wikis como herramientas de trabajo colaborativo complementario y desarrollo de recursos para la formación en traducción a nivel universitario: análisis retrospectivo Bianca Vitalaru. Página 37 de 47 
construir un producto final y esto transciende el mero debate. Este proceso de construcción implica una comunicación eficaz y constante entre los miembros de un mismo grupo.

La comunicación de los grupos de alumnos de todas las actividades colaborativas se ha realizado de dos maneras: virtual (email y foro del wiki) y presencial. Según los resultados de una entrevista a representantes de los grupos del curso 2008-2009, gran parte del proceso de planificación en el caso de los glosarios $(83 \%)$ se había realizado presencialmente al coincidir con gran parte de las clases presenciales, aunque también se intercambiaron emails y se utilizó el foro de debate de la wiki para aspectos puntuales. Sin que se estipule como requisito obligatorio utilizar el foro de debate como instrumento principal de comunicación, éste se ha utilizado para:

a) formar o completar los grupos en el caso de las actividades de redacción, en el curso 2008-2009:

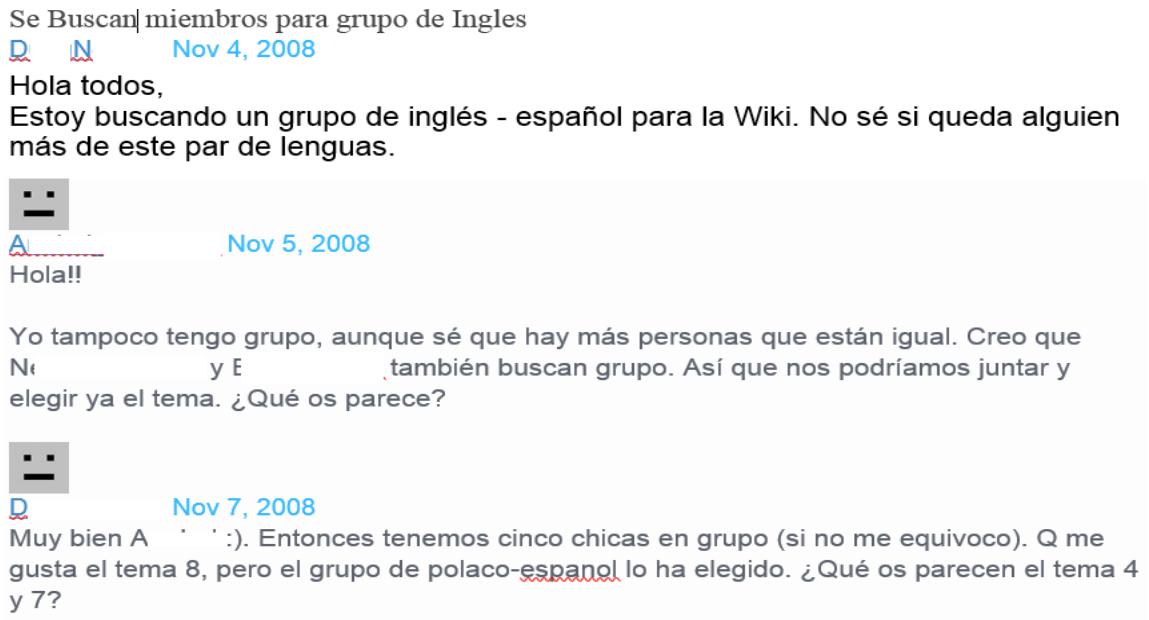

Figura 25. Búsqueda de grupo y tema 2008-2009

b) repartir los temas u organizar el trabajo:

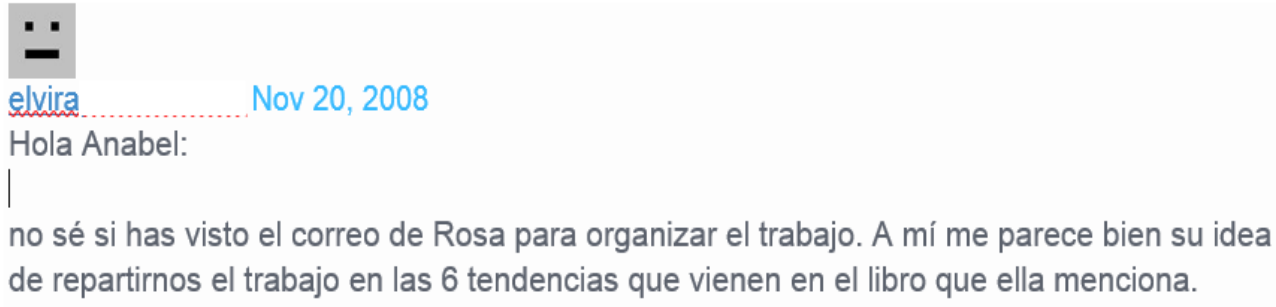

Figura 26. Comentario sobre repartición del trabajo 2008-2009

Wikis como herramientas de trabajo colaborativo complementario y desarrollo de recursos para la formación en traducción a nivel universitario: análisis retrospectivo Bianca Vitalaru. Página 38 de 47 
Mad Nov 17, 2008

oye una cosita, Alberto, me dijiste que tú te encargaste de lo del traductor jurado en España, yo estoy investigando lo del traductor jurídico, pero también hay que ver la diferencia con el traductor en los SSPP. Eso, también lo miramos los dos ¿no? o qué te parece?

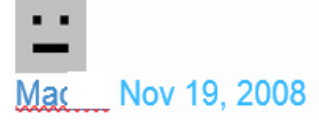

Otra cosa, alberto, yo estoy sacando mucha información acerca de la traducción jurídica en España y en general, pero habrá que establecer una comparación entre unas y otras, ¿no? Por eiemplo la traducción en los SSPR has buscado algo de eso? Porque no consistirá sólo en pegar la información de cada tipo de traducción por separado sino una comparación, que es lo que se pide, ¿no?

Y otra cosa, ¿cuánta información tenéis cada uno? Porque yo tengo unas 10 páginas de word, times new roman a 12...entonces tiene que estar un poco equilibrado, es mucho es poco, está bien o fatal???jeje

Contadme un poco lo que habéis hablado porque como yo no os veo no sé si vais comentando algo o no, ¿vale?

un cordial saludo:)

Figura 27. Comentario en foro actividad de redacción colaborativa 2008-2009

c) comentar diferentes aspectos problemáticos con los compañeros:

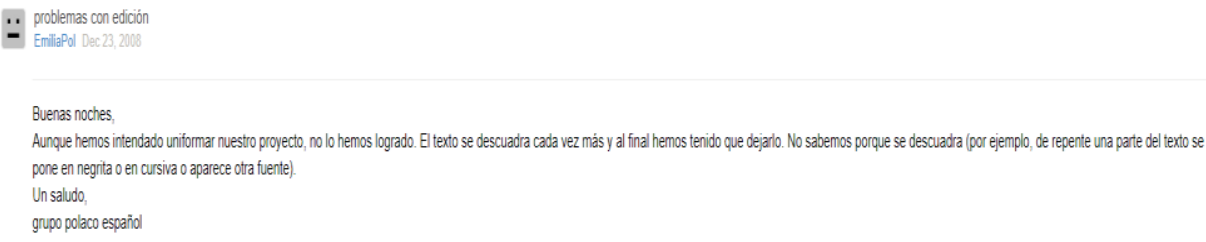

Figura 28. Comentarios sobre formato 2008-2009

Comentarios sobre Glosano Derecho Laboral

En cuanto a los terminos más significabivos que hemos elegido para introducir en el glosario sobre Derecho Laboral cabe senlalar que para algunos tèminos tuvimos algunas dudas en cuanto a la pertenencia de algunos tèminos al campo y ámbito de Derecho al ser la mayoria ligados a la organización interna del mundo empresanial. Sin embargo al leer y aprofundzar las caracteristicas del Derecho Laboral antes de elaborar el glosario, coincidimos en los primeros conceptos que nos vinieron a la mente y que relacionabamos con Derecho Laboral. Términos como 'Formación profesional' tueron descartados después de haberios incorporados al glosario ya que no resultaron conceptos demasiado representativos y tambièn otros témminos cuya equivalencia y traducción al francés resultaba dificl seguin nos dieron por entender las Traductoras como 'Principio de Primacia'.

Figura 29. Dificultad glosario derecho laboral 2007-2008

d) motivación

Wikis como herramientas de trabajo colaborativo complementario y desarrollo de recursos para la formación en traducción a nivel universitario: análisis retrospectivo Bianca Vitalaru. Página 39 de 47 


\begin{abstract}
Grupo 9- Francés - Español
judithar Nov 6, 2008

Bueno, como ya hemos terminado las actividades de los 5 temas, creo que llegó el momento de empezar a organizarnos con la wiki. Así que a ver si nos ponemos de acuerdo en el contenido y el reparto de las cosas, y vamos moviendo un poco el tema.

ánimo que esto acaba de empezar!!! jeje

\section{CarmenoF Nov 12, 2008}

¡Exacto! ¡Ahora ya nos hemos visto personalmente y nos toca trabajar como es debido para crear nuestra propia página web :)! Una de esas que nunca quieres dejar de consultar, que resulte de interés y constituya una información importante para ampliar conocimientos a todos aquellos que en un futuro quieran saber más sobre nuestro tema. Como dices... iijel viaje apenas empieza!!!
\end{abstract}

Figura 30. Comentario sobre tipo de página que se pretende crear 2008-2009

\title{
4.3.2 Trabajo en grupo y otras habilidades relacionadas
}

Más allá de los resultados materiales y estadísticos, en el estudio anterior (Vitalaru, 2009) destacábamos los resultados intrínsecos como la calidad del trabajo desempeñado, el entusiasmo con el que habían trabajado los grupos o la asunción de responsabilidad por cada miembro del grupo. De hecho, en el caso de la redacción colaborativa, los aspectos más importantes a subrayar en este sentido son: la selección, filtración y proporción de la información exclusivamente por los grupos formados, el hecho de que se haya seguido un proceso que incluía comentarios previos y decisiones concretas y definitorias tomadas por los componentes individuales de dichos grupos, de que cada miembro se haya responsabilizado por su parte $\mathrm{y}$, en definitiva, de que hayan conectado como grupo tanto como para producir, mediante aportaciones individuales dentro del grupo, una unidad de contenido específico dentro de un tema general. En otras palabras, cada grupo había aportado su granito de arena en la elaboración del tema y cada individuo había hecho su aportación responsable para el beneficio del grupo, que es una lección fundamental a aprender antes de lanzarse a la realidad del mundo laboral. Después de considerar todo esto nos preguntábamos si la posibilidad de que participaran menos grupos habría implicado un posible fracaso de la tarea. Podemos subrayar que en ningún caso se podría hablar de éxitos o fracasos sino de estrategias para implicar al alumnado en su proceso formativo y de concienciarle sobre la importancia de determinados aspectos.

En retrospectiva y teniendo en cuenta la evolución del resto de actividades de este tipo se puede afirmar que los resultados (los productos finales y sus calificaciones) demuestran que los alumnos, en grupo, desarrollaron habilidades de trabajo en equipo, análisis, síntesis y expresión escrita como "competencias encaminadas al desarrollo de procesos colectivos" señaladas por Montenegro y Pujol (2010: 9). Algunas de estas competencias, o más bien, habilidades, son las de documentación y argumentación.

En el caso de las actividades terminológicas (glosarios) destaca el esfuerzo demostrado por el alumnado y la calidad del trabajo, así como el desarrollo de diferentes tipos de habilidades. En primer lugar, las específicas relacionadas con el trabajo en grupo, como la colaboración durante todo el proceso, la comprensión del

Wikis como herramientas de trabajo colaborativo complementario y desarrollo de recursos para la formación en traducción a nivel universitario: análisis retrospectivo Bianca Vitalaru. Página 40 de 47 
compromiso que se requiere y la toma de decisiones importantes que afectaban a la imagen global del 'producto'.

En segundo lugar, destacan las habilidades de trabajo autónomo prestando atención al proceso de trabajo (Kessler y Bikowski, 2010 citado por Araujo Portugal, 2014: 9) y para el beneficio del grupo, el aprendizaje y uso de la terminología especializada a lo largo de las diferentes fases del proceso recopilatorio (búsquedas contextuales, definiciones, fichas terminológicas, traducciones) y la documentación como capacidad que implica saber encontrar, gestionar y utilizar terminología especializada. En este sentido, una lección aprendida por los alumnos ha sido tomar conciencia de la parte terminológica del trabajo del traductor y su importancia especialmente teniendo en cuenta que la "densidad cognitiva de los textos especializados está en relación directamente proporcional con la cantidad de terminología que contienen y el grado de comprensión estructural y textual de esta terminología" (Cabré, 2000: 4). Al convertirse ellos mismos en productores de textos debían "conocer la materia específica, controlar su contenido y manejar la terminología que lo expresa" (Cabré, 2000: 5). En este sentido, la tarea ha facilitado la comprensión de las diferentes tareas y responsabilidades que tiene el traductor profesional en su continuo proceso de autoformación y documentación.

Teniendo en cuenta los aspectos comunes de los dos tipos de actividades, para ambas se desarrollaron habilidades de trabajo autónomo, reflexivo y activo (González, Estrada Esquivel y Campos Méndez, 2013: 98-109) a través de la participación activa en un proceso de construcción colaborativa. Por otro lado, tener que cumplir plazos de entrega para las diferentes fases de las actividades y determinados requisitos han contribuido a la concienciación sobre algunas de las habilidades que señala la Red EMT (EMT Competence Framework, 2017: 10) en el marco de la competencia personal e interpersonal: planificar el tiempo, la carga de trabajo y manejar el estrés, así como trabajar en equipo cuando corresponda, en un entorno virtual, multilingüe $\mathrm{y}$ multicultural. A su vez, la experiencia adquirida mediante la comunicación intercultural de los alumnos y la identificación de diferencias socioculturales en los temas tratados de manera comparativa (por ej. entre sistemas) y en la traducción de terminología ha contribuido también al desarrollo de parte de la competencia intercultural.

Finalmente, podemos afirmar que los dos tipos de tareas han conseguido concienciar sobre el valor del trabajo en grupo, que no sólo aporta mayor cantidad, sino que incluso puede ser de mejor calidad que las producciones individuales, teniendo en cuenta que las conversaciones y el debate con los demás miembros pueden ser mucho más productivos. Además, el orgullo de la autoría del material (Educause, 2007: 1) producido por los alumnos también tiene un valor añadido, ya que los alumnos juegan el papel de editores de pleno derecho.

\section{Herramientas wiki: lecciones aprendidas y reflexiones finales}

En primer lugar, cabe señalar que, durante el periodo de implementación como actividades obligatorias, las actividades diseñadas en base a las herramientas wikis han sido realizadas por todos los alumnos que asistían a clase de manera continuada, demostrando su interés, su motivación y su esfuerzo. Sus resultados han resultado ser de bastante calidad debido a varios factores como el trabajo en grupo y la colaboración con los compañeros, la seriedad, el esfuerzo y la participación, el método de trabajo, la originalidad, la claridad, la coherencia y la relevancia de las ideas incluidas. Además, el

Wikis como herramientas de trabajo colaborativo complementario y desarrollo de recursos para la formación en traducción a nivel universitario: análisis retrospectivo Bianca Vitalaru.

Página 41 de 47 
carácter complementario de las actividades y su periodo de realización les ha permitido, por un lado, (actividades de redacción), anticiparse a algunas de las dificultades y comprensión del contexto de trabajo y, por otro (actividades terminológicas), reutilizar y completar parte de los conocimientos adquiridos durante las clases presenciales y mejorarlos, lo que sugiere que la herramienta es un buen instrumento formativo complementario.

En cuanto al desarrollo de habilidades, se han adquirido, en primer lugar, las inherentes a la capacidad de trabajo en grupo, en segundo lugar, a la adquisición de conocimientos temáticos y a la documentación necesarios $\mathrm{y}$, en tercer lugar, a la competencia interpersonal requerida a los traductores profesionales por la Red EMT.

Por lo tanto, podemos decir que la experiencia con wikis ha sido bastante productiva, demostrando así la utilidad de estas herramientas como instrumento viable para la construcción de contenido, así como para la elaboración de glosarios bilingües/multilingües en particular, que también podría extrapolarse a la elaboración de otros materiales de trabajo, estudio y aprendizaje en general como guías o corpus de textos.

En segundo lugar, basándonos en la experiencia de los diferentes cursos académicos descritos en este trabajo, también hemos podido extraer algunas recomendaciones generales. Si en Lázaro Gutiérrez, Pena Díaz y Vitalaru (2009) hacíamos recomendaciones prácticas sobre el diseño, la estructura y la evaluación, en este trabajo incluiremos una reflexión retrospectiva sobre los aspectos principales que el profesor debe plantearse antes de utilizar las herramientas wiki para desarrollar trabajos colaborativos de construcción de contenido, cuyos detalles se incluyen a continuación. Como podremos observar, algunos de los aspectos más problemáticos son los relacionados con el manejo eficaz de la herramienta y la evaluación correcta y adecuada del alumnado, a los que otros autores (apartado 2.1) también aludieron a raíz de sus experiencias docentes.

\section{1) Instrumento formativo complementario}

El primer elemento importante que el profesor debe tener en cuenta es la posibilidad de contar con una herramienta de trabajo fácil de manejar y flexible para que los alumnos puedan editar cualquier tipo de información; a su vez, el profesor tiene acceso para corregir y evaluar diferentes aspectos (autor de la edición, cantidad de ediciones, contenido aportado por un usuario, revisión del contenido por otro usuario, estructura, tipo de contenido, participación en el foro, etc.). La herramienta permite ver el historial de ediciones y contabilizar el nivel y tipo de participación, así como dar feedback o proponer y comentar temas en el foro de cada página. Sin embargo, tiene una serie de limitaciones técnicas, por lo que el profesor debe prever dificultades del alumnado, monitorizar los cambios y estar disponible para dudas. Algunas de las limitaciones que podemos señalar después de haber trabajado en otros entornos (plataformas virtuales, redes sociales y herramientas de Google) son la dificultad en el manejo de las tablas, la exportación manual del contenido redactado y material generado, la necesidad de contabilizar manualmente el número de intervenciones de los participantes, la ausencia de una opción para restringir la visibilidad de los trabajos por grupos y secciones de la web. En general, también observamos la poca operatividad, por ejemplo, para señalar cambios ya realizados o añadir comentarios en cuadros de texto a una edición anterior de la página (como el control de cambios en un Google doc.), así como nivel bajo de interactividad para permitir comunicarse con los compañeros de forma constante y amena como en el caso de las redes sociales.

Wikis como herramientas de trabajo colaborativo complementario y desarrollo de recursos para la formación en traducción a nivel universitario: análisis retrospectivo Bianca Vitalaru.

Página 42 de 47 
Generalmente, se puede subrayar la aplicabilidad de las herramientas para diseñar instrumentos formativos de tipo colaborativo y complementario. Sin embargo, la figura del profesor/monitor colaborativo y comunicativo es fundamental. Si los objetivos de tipo material se cumplen con bastante facilidad, monitorizar el proceso de aprendizaje individual y colectivo y evaluar resultados o competencias individuales resulta más complicado y laborioso.

2) Importancia de las instrucciones

Proporcionar instrucciones claras antes de poner en práctica la actividad, así como pensar en las posibilidades que se tienen para incentivar la participación de los alumnos en la misma es imprescindible. En nuestro caso, hemos pasado de tareas optativas a tareas obligatorias en las asignaturas de traducción, permitiendo a los alumnos llevar los glosarios generados a los exámenes escritos, para concienciar sobre la necesidad de compromiso y seriedad en la realización de la tarea. En general, en vista de las necesidades detectadas, las instrucciones se han ido concretando cada vez más y se han incluido tareas precisas para las diferentes fases de trabajo. Las sesiones introductorias presenciales pueden facilitar la tarea.

3) Evaluación de las diferentes partes de la actividad

Establecer criterios de evaluación y calificación de la actividad y tener preparada una rúbrica de acuerdo con las distintas fases que la componen también es fundamental para uniformizar la aplicación objetiva de los criterios especialmente si se trata de dos o más evaluadores e incluso para evitar confusiones de cara a los alumnos. Asimismo, es importante planificar de antemano la evaluación o la importancia de cada tipo de aportación individual o grupal y su porcentaje en la calificación o detalles que pueden influenciarla. En el caso de la evaluación grupal existe el riesgo de que algunos alumnos trabajen más que otros y, en un entorno de aprendizaje, la participación de todos los miembros de un grupo es esencial. Una dificultad añadida para el profesor es poder apreciar diferencias en cuanto a cambios de perspectivas y decisiones que se toman a lo largo del proceso. En cambio, si se trata de evaluaciones individuales, existe la posibilidad de que el aprendizaje sea menos contextualizado al basarse en la perspectiva, en general más limitada, de un solo alumno; en el caso de clases numerosas para el profesor el proceso de monitorización y evaluación también es más complicado. Por último, poder contar con otros traductores o especialistas en caso de tratarse de varias lenguas también debe ser un factor en la toma de decisiones con respecto a la evaluación de las tareas y es imprescindible en la fase final del trabajo.

4) Wikis para la edición compartida

Con respecto a los dos tipos de actividades descritas, después de haber probado diferentes métodos de elaboración especialmente en la elaboración de glosarios, desde el trabajo en grupo dentro de la misma especialidad y junto con otras especialidades (tipo proyecto general y sub-proyectos) hasta el trabajo individual y en pequeños grupos coordinados, podemos destacar la utilidad de las herramientas wikis como instrumento factible de edición compartida incluso para trabajos bastante amplios. Varios aspectos son importantes: a) establecer funciones para los diferentes agentes que participan en la actividad; b) fomentar la participación activa y reactiva, dejando la posibilidad de demostrar iniciativa y creatividad en la toma de decisiones; c) crear la figura del coordinador del grupo/revisor del trabajo. Finalmente, el número total de alumnos es

Wikis como herramientas de trabajo colaborativo complementario y desarrollo de recursos para la formación en traducción a nivel universitario: análisis retrospectivo Bianca Vitalaru. Página 43 de 47 
importante y, en caso de tratar con varias especialidades, tener en cuenta los detalles para hacer un reparto equitativo y equilibrado.

5) Comunidades de trabajo y temática

Según hemos podido comprobar mediante las actividades descritas, las herramientas utilizadas pueden ser esenciales en la creación de pequeñas comunidades con intereses comunes. El planteamiento de una temática contextual fundamental común y de utilidad para los grupos formados (terminología, sistemas, etc.) puede ser clave para la motivación del alumnado, su proceso de aprendizaje y la elaboración de materiales o recursos especializados prácticos para el alumnado. También se puede platear su utilización en la enseñanza invertida en el contexto de las clases presenciales de traducción. En este sentido, consideramos que sería necesario proponer proyectos interdisciplinarios enfocados a la creación de materiales para la formación de traductores basada en la experiencia colaborativa y en la filosofía wiki, ya que las herramientas se pueden incorporar con facilidad a otras plataformas y entornos docentes.

\section{Agradecimientos}

Agradecemos la colaboración y participación de los alumnos del máster de las ediciones 2007-2011, cuya actividad supuso no solo un enriquecimiento para el profesorado y el programa impartido sino también una oportunidad fundamental para poder evaluar la utilidad de las herramientas en los contextos docentes señalados.

Presentación del artículo: 14 de agosto de 2018

Fecha de aprobación: 12 de marzo de 2019

Fecha de publicación: 30 de marzo de 2019

Vitalaru, Bianca (2019). Wikis como herramientas de trabajo colaborativo complementario y desarrollo de recursos para la formación en traducción a nivel universitario: análisis retrospectivo. RED. Revista de Educación a Distancia, 59. DOI: http://dx.doi.org/10.6018/red/59/02

\section{Financiación}

Esta investigación no ha recibido ninguna subvención específica de los organismos de financiación en los sectores públicos, comerciales o sin fines de lucro.

\section{Referencias bibliográficas:}

Anderson, P. (2007). What is Web 2.0? Ideas, technologies and implications for education. JISC, Technology and Standards Watch. Recuperado 30 de julio de 2018, de http://www.ictliteracy.info/rf.pdf/Web2.0_research.pdf

Anguita Martínez, R., García Sastre, S. et al. (2010). Wikis y aprendizaje colaborativo: lecciones aprendidas (y por aprender) en la facultad de educación RED. Revista de Educación a Distancia, 12, 2-19. Recuperado 1 de agosto de 2018, de http://revistas.um.es/red/article/view/92951

Wikis como herramientas de trabajo colaborativo complementario y desarrollo de recursos para la formación en traducción a nivel universitario: análisis retrospectivo Bianca Vitalaru. Página 44 de 47 
Araujo Portugal, J. C. (2014). El uso de blogs, wikis y redes sociales en la enseñanza de lenguas. EDUTEC, Revista Electrónica de Tecnología Educativa, 49, 1-27. Recuperado 1 de agosto de 2018, de http://www.edutec.es/revista/index.php/edutec-e/article/view/227

Cabré, M. T. (2000). El traductor y la terminología. Necesidad y compromiso. Panace@, 1 (2), 1-3. Recuperado 15 de julio de 2018, de http://files.sld.cu/traducciones/files/2014/01/el-traductor-y-la-terminologiafernando-navarro.pdf

Folleto informativo (2018-2019) Máster Universitario en Comunicación Intercultural, ITSP. Recuperado 3 de marzo de 2019, de https://www.uah.es/export/sites/uah/es/estudios/.galleries/Archivosestudios/MU/Unico/AM040_13_1_1_E_TripticoMaster18-19-rev.pdf

Gannon-Leary, P. y Fontainha, E. (2007). Communities of practice and virtual learning communities: benefits, barriers and success factors. eLearning Papers, 5. Recuperado 15 de julio de 2018, de www.elearningpapers.eu

García Santiago, M. D. (2016). El uso de blogs y wikis en la formación del traductor. Tradumatica. 14, 147-155. Recuperado 1 de agosto de 2018, de https://revistes.uab.cat/tradumatica/article/view/69

González, J. y Wagenaar, R. (Coord.) (2003). TUNING. Educational Structures in Europe. Informe Final. Fase 1. Bilbao: Universidad de Deusto.

Guía docente asignatura comunicación institucional con población extranjera (20182019). Recuperado 3 de marzo de 2019, de https://www.uah.es/export/sites/uah/es/estudios/estudiosoficiales/grados/.galleries/Programas/M045/200755_M045_2018-19.pdf

Guía docente Traducción especializada: ámbito jurídico, español-inglés (2018-2019). Recuperado 3 de marzo de 2019, de https://www.uah.es/export/sites/uah/es/estudios/estudiosoficiales/grados/.galleries/Programas/M045/200755_M045_2018-19.pdf

Educause, Learning Initiative 7 things you should know about...Wikis. Recuperado 15 de julio de 2018, de http://www.educause.edu/ir/library/pdf/ELI7004.pdf

EMT Competence Framework (2017). European Masters in Translation Network. Recuperado 15 de julio de 2018, de https://ec.europa.eu/info/sites/info/files/emt_competence_fwk_2017_en_web.pdf

Ferreira-Lopes, L., Bezanilla, M. J. y Elexpuru, I. (2018). Integrating Intercultural Competence Development into the Curriculum through Telecollaboration. A Task Sequence Proposal for Higher Education. RED. Revista de Educación a Distancia, 58, 1-36. Recuperado 12 marzo 2019, de http://www.um.es/ead/red/58

Lázaro Gutiérrez, R., Pena Díaz, C. y Vitalaru, B. (2009). Wiki en lenguas para fines específicos y su traducción. Red U - Revista de Docencia Universitaria,5. (II parte) en coedición con Revista de Educación a Distancia. Recuperado 15 de julio de 2018, de http://www.um.es/ead/Red_U/m5/

Mancho Barés, G, Vitalaru, B. y Valero Garcés, C. (2008). Implantación de la herramienta wiki en la Universidad de Alcalá: funciones pedagógicas. V Congreso Internacional Docencia Universitaria e Innovación. Lleida: Servicio de publicaciones de la universidad.

Meléndez, M. (2015). La Wiki: herramienta que propicia el aprendizaje colaborativo. función: del tutor. Contenidos educativos digitales y comunidades de aprendizaje. XVI Encuentro Internacional Virtual Educa Guadalajara, 1-19.

Wikis como herramientas de trabajo colaborativo complementario y desarrollo de recursos para la formación en traducción a nivel universitario: análisis retrospectivo Bianca Vitalaru. Página 45 de 47 
Recuperado 7 de agosto de 2018, de https://reposital.cuaed.unam.mx:8443/xmlui/handle/123456789/4402?show=full

Montenegro, M. y Pujol, J. (2010). Evaluación de la wiki como herramienta de trabajo colaborativo en la docencia universitaria RED. Revista de Educación a Distancia, 11, 1-15. Recuperado 7 de agosto de 2018, de http://www.redalyc.org/articulo.oa?id=54714024005

Occelli, M., Masullo, M. y Valeiras, N. (2013). La construcción colaborativa de conocimiento en contextos de aprendizaje mediados por TIC. Enseñanza de las ciencias: revista de investigación y experiencias didácticas, 9, 2552-2557. Recuperado 7 de agosto de 2018, de https://www.raco.cat/index.php/Ensenanza/article/view/307933

Perea González, G., Estrada Esquivel, B. y Campos Méndez, M. (2013). El blog y wiki como herramienta docente para el trabajo colaborativo, el aprendizaje autónomo, activo y reflexivo. RIDE, 3, (6), 98-109. Recuperado 7 de agosto de 2018, de https://dialnet.unirioja.es/servlet/articulo?codigo $=4932654$

Porto Requejo, M., Mancho Barés, G. y Pena Díaz, C. (2008). Evaluación de actividades en soporte wiki implementadas en asignaturas de inglés especializado en la Universidad de Alcalá. En P. Sánchez Hernández (Ed.), Researching and teaching specialized languages: new contexts, new challenges (pp. 557-567). Universidad de Murcia: Servicio de publicaciones.

Porto Requejo, M. y Pena Díaz, C. (2010). Wikis para el aprendizaje de inglés para fines específicos. En L. Margalef et al. (Eds.), Innovar en la enseñanza universitaria (pp. 387-398). Alcalá de Henares: Servicio de publicaciones de la universidad.

Real Decreto 1027/2011, de 15 de julio, por el que se establece el Marco Español de Cualificaciones para la Educación Superior. BOE núm. 185, de 03/08/2011. Ministerio de Educación. Recuperado 15 de julio de 2018, de https://www.boe.es/buscar/act.php?id=BOE-A-2011-13317

Valero Garcés, C. y Vitalaru, B. (2007). Los wikis en el Programa de Comunicación Intercultural. L. Margalef et al. (Eds.), Experiencias de innovación docente en la Universidad de Alcalá (pp. 399-407). Alcalá de Henares: Servicio de publicaciones de la universidad.

Valero Garcés, C., Bodzer, A., Vitalaru, B. y Lázaro Gutiérrez, R. (Eds.) (2011). Traducción e Interpretación en los Servicios Públicos en un mundo INTERcoNEcTado. TISP EN INTERNET/ Public Service Interpreting and Translation in the Wild Wired World-PSIT in WWW. Alcalá de Henares: Servicio de publicaciones de la universidad.

Valero Garcés, C., Vitalaru, B. y Mojica-López, E. (Eds.) (2014). (Re)considerando ética e ideología en situaciones de conflicto/ (Re)visiting ethics and ideology in situations of conflict. Alcalá de Henares: Servicio de publicaciones de la universidad.

Valero Garcés, C., Álvaro Aranda, C. y Ginés Grao, M. (Eds.) (2017). Superando límites en traducción e interpretación en los Servicios Públicos / Beyond Limits in Public Service Interpreting and Translation. Alcalá de Henares: Servicio de publicaciones de la universidad.

Vitalaru, B., Valero Garcés, C. y Lázaro Gutiérrez, R. (2008). Las wikis como herramienta para la creación de glosarios ad hoc multilingües en T\&ISP. En P. Sánchez Hernández, P. Pérez Paredes et al. (Eds.), Researching and Teaching

Wikis como herramientas de trabajo colaborativo complementario y desarrollo de recursos para la formación en traducción a nivel universitario: análisis retrospectivo Bianca Vitalaru. Página 46 de 47 
Specialized Languages: New Contexts, New Challenges (pp. 593-607). Murcia: Editum.

Vitalaru, B. (2009). Las herramientas wiki y su utilidad en la creación de materiales bilingües / multilingües para traductores de los servicios públicos. En C.M. Bretones Callejas et. al. (Eds.), Applied Linguistics Now. Understanding Language and Mind = La Lingüística aplicada actual: comprendiendo el lenguaje y la mente (pp. 1887-1900). Universidad de Almería: Servicio de publicaciones.

Vitalaru, B. y Bodzer, A. (2012). Elaboración y aplicabilidad de glosarios especializados individuales y colaborativos en asignaturas de traducción en un programa de postgrado. Comunicación XXX Congreso AESLA. 19-21 abril. 